\title{
The principle of continuous biological information flow as the fundamental foundation for the biological sciences. Implications for ageing research.
}

Short-title: Life as a continuous flow of information.

Xavi Marsellach ${ }^{1 *}$

1 Independent Researcher, (L' Hospitalet de Llobregat, Barcelona, Catalonia).

*Correspondence to: xavi.marsellach@gmail.com

\begin{abstract}
The current state of biological knowledge contains an unresolved paradox: life as a continuity in the face of the phenomenon of ageing. In this manuscript I propose a theoretical framework that offers a solution for this apparent contradiction. The framework proposed is based on a rethinking of what ageing is at a molecular level, as well as on a rethinking of the mechanisms in charge of the flow of information from one generation to the following ones. I propose an information-based conception of ageing instead of the widely accepted damage-based conception of ageing and propose a full recovery of the chromosome theory of inheritance to describe the intergenerational flow of information. Altogether the proposed framework allows a precise and unique definition of what life is: a continuous flow of biological information. The proposed framework also implies that ageing is merely a consequence of the way in which epigenetically-coded phenotypic characteristics are passed from one generation to the next ones.
\end{abstract}

\section{Life as a continuity $v s$ the intrinsic discontinuity that aging imposes on lifespan.}

\section{Life as a continuity}

We all recognize a living organism. This is thanks that we humans can recognise ourselves as such. This is something not obvious though, just a handful of species are recognized with the ability of mirror self-recognition (MSR) and the meaningfulness that this might mean for self-awareness is 
still an open debate (de Waal, 2019). We humans do not only have the ability of MSR, but to do much more complex achievements such as creating and recording knowledge. In the field of life sciences, we can create biological knowledge. This biological knowledge should allow us to define, in a clear and precise manner, what is the fundamental definition of a life being. In short: we should be able to provide an indubitable answer to the question "What is life?". A definition of life that would allow us to identify an alien form of life should we ever were able to find one. However, to date there is not yet a consensus answer to this question (Koshland, 2002; Benner, 2010; Tirard et al., 2010; Abel, 2011; Currais, 2017; Vitas \& Dobovišek, 2019; Tetz \& Tetz, 2020).

One thing that is widely accepted is that the origin of all living organisms currently on earth can be traced back to a unique event. Although multiple independent origins of life have been hypothesized, just one of them seems to have prevailed. An overwhelming number of observations points towards a shared origin of all living organisms on earth. To name some: 1) the fact that common aspects are shared at the molecular level, including fundamental biological polymers: nucleic acid as genetic material and L-amino acids as components of proteins; 2) the general unit of biochemistry in terms of basic metabolic and energy processes; 3) the existence of a nearly universal genetic code; 4) the congruence of morphological and molecular phylogenies; 5) the discovery of homologous protein families in the three domains of life (bacteria, archaea and eukaryotes); 6) the correspondence between phylogeny and the palaeontological record and 7) the existence of numerous predicted transitional fossils. Some attempts have been done to show the existence of a common ancestor with a formal quantitative testing (Theobald, 2010; Penny et al., 1982), although an agreement about if this can formally be tested has not been achieved (Velasco, 2018; de Oliveira Martins \& Posada, 2016; Koskela \& Annila, 2012; Koonin \& Wolf, 2010; Theobald, 2010; Penny et al., 1982). The idea of a common ancestry dates to Darwin itself (Darwin, 1871), but the idea of continuity in life is even older. Rudolf Virchow introduced the famous third dictum of cell theory: "Omnis cellula e cellula" (Virchow, 1859), which implicitly contains the idea of continuity ("All cells come from cells").

\section{Ageing and the discontinuity of life}

At the evolutionary level, it seems quite clear that there is continuity throughout the history of life on earth, but this is not at all obvious when analysing biological processes at the individual level. The phenomenon of ageing seems to impose a discontinuity on almost all living organisms.

As it happens with a definition of life, a common definition of what is ageing is not yet agreed (Fulop et al., 2019), and many controversies are still in place (Marsellach, 2017). Anyway, there is a definition of ageing widely used by many ageing researchers in the ageing research community: ageing, although an individual feature, can be defined at populational level as an increase in the 
mortality rate with time (Rose, 1994; McDonald, 2013). However, this definition is only a macroscopic phenotypic description of ageing. It should be noted as well that, as it refers to mortality, this definition of ageing, is not independent of the definition of life considered. In summary, this definition of ageing only describes what an external observer sees about the phenotypic characteristics of living organisms that do age but tells nothing about the molecular determinants that drives ageing. Nine hallmarks have been proposed (López-Otín et al., 2013), but no complete consensus is agreed yet (Zhang \& Gladyshev, 2020; Fulop et al., 2019; Fuellen et al., 2019; Marsellach, 2017; Gladyshev, 2016).

Since there is no consensus on what ageing itself is, it is also difficult to agree on how aging arose. It was initially thought that aging evolved after the origin of eukaryotes, but observations of aging phenomena in prokaryotes questioned this initial belief (Ackermann et al., 2007). Some proposals have been made to tackle these observations: i.e., ageing is possible in single-celled organisms thanks to the dilution of the damage that takes place during cell division (Gladyshev, 2016; Gladyshev, 2013), and/or ageing evolved in single-celled organisms thanks to mechanisms that differently sequestrated damage to one of the two dividing cells (Moger-Reischer \& Lennon, 2019), creating in this way an incipient difference between the soma and the germline (as predicted by the disposable soma theory of ageing (Kirkwood, 1977)). This kind of studies are particularly important in Saccharomyces cerevisiae (where there is a non-symmetrical division, but have been observed as well in symmetrically dividing organisms (Coelho et al., 2013))

\section{A coherent information-based conception of both phenomena: life and ageing}

In nowadays ageing research, ageing is almost a synonymous or a derivate of the concept of damage and damage accumulation (Ogrodnik et al., 2019; Moger-Reischer \& Lennon, 2019; Gladyshev, 2016). Something must be damaged for an organism to age and die (because of that damage).

In the last decade though, there has been a growing interest in the involvement of the epigenome in ageing. An astonishing observation of a high correlation of some epigenomic marks and ageing started all this interest (Gibbs, 2014; Horvath, 2013; Bocklandt et al., 2011). However, to date there is no clear agreement on whether the epigenome has a central role in ageing (is it the cause or the consequence?), and neither is a consensus on what the epigenetic clocks might mean, which are the role that methylation marks do play on ageing and health or even the involvement of them in the rejuvenation process (Gladyshev, 2020; Niehrs \& Calkhoven, 2020; Bertucci \& Parrott, 2020; Zhang \& Gladyshev, 2020; Jiang \& Guo, 2020; Field et al., 2018; Horvath \& Raj, 2018). Epigenetics, although recognized as one of the factors implicated in ageing (López-Otín et al., 2013), is hardly considered the sole cause of aging in some studies (Chiavellini et al., 2021; 
Ashapkin et al., 2017; Marsellach, 2017; López-León \& Goya, 2017; Ocampo et al., 2016; Gibbs, 2014). In this manuscript I develop in detail an information-based conception of ageing, previously proposed by this author (Marsellach, 2018), in addition to proposing a coherent and testable definition of what life is based solely on the concept of biological information. In my proposal, the notion of continuity is a fundamental concept for defining both life and ageing.

In recent years there has been an active work on an information centric definition of life and individuality. (Jost, 2021; Kempes \& Krakauer, 2021; Krakauer et al., 2020; Jost, 2020; Adami, 2012; Adami, 2002) It is not the intention of this essay to reproduce the work done from those authors, but to complement it from theoretical considerations, and to centre in its implications on the study of ageing as part of one of the most relevant biological information-centred related processes. This essay also pretends to propose experimental ways to test the information-based nature of life by proposing ways to address the information-based nature of ageing.

As a summary: there is life while the biological information, necessary to maintain homeostasis and to overcome lethal environmental barriers (anything that could destroy the biological structures constructed with the biological information) is still useful for such a purpose. Death is caused by loss of homeostasis or by the inability to overcome lethal environmental barriers due to 1) extrinsic lethality factors (i.e., accidentality that destroys the usefulness of the biological structures constructed with the biological information, the greater the complex lifestyle, the greater the risk of extrinsic lethality factors); or 2) intrinsic loss of the usability of the biological information maintain homeostasis or to overcome the lethal environmental barriers. This last-mentioned process is, according to my proposal, the ageing process, and is due to the way in which biological information is treated by the ageing living beings (see below for detailed development). Ageing is overcome during intergenerational steps due to specific information retrieval processes (epigenetic reprograming or rejuvenation process (Denoth-Lippuner \& Jessberger, 2019)). Ageing, therefore, implies a discontinuity in the flow of biological information, while life continues in ageing species thanks to the continuous flow of useful biological information provided by the parents to their offspring during the rejuvenation process that takes place in the intergenerational steps.

To describe my proposal, I need to delve deeper into the history of genetics and epigenetics to identify some misconceptions that might have led us to the inability to find coherent definitions to describe life and ageing. This historical review has led me to propose a modified description of the central dogma of molecular biology, first defined by Francis Crick (Crick, 1970), as well as to propose a complete retrieval of the chromosomal theory of inheritance (Boveri, 1904; Sutton, 1903) to describe the intergenerational flow of biological information. The next sections of this article contain a development of all these concepts in detail. 


\section{Biological information and the battle for Mendel's legacy}

Since Mendel uncovered the laws of inheritance in hybrids (Mendel, 1866), the question of where and how the biological information is stored was an open question in the biological field. The rediscovery of Mendel's Laws in the early 1900s independently by Hugo de Vries, Carl Correns and Erich von Tschermak, and works made by prominent scientist William Bateson marks the start of genetic studies as the science to study heredity (Bateson et al., 1902).

The first clue about where the biological information could be stored came from the chromosomal theory of inheritance in the early 1900s. Works by Walter Sutton and Theodor Boveri proposed to consider the chromosomes as the bearers of the Mendelian factors (Boveri, 1904; Sutton, 1903). This theory was finally fused with Mendelian laws by Thomas Hunt Morgan (Morgan, 1915), leading to the establishment of genetics as a new discipline, separated from other biological disciplines. This had as a side effect the development of classical genetics, with an abstract nonchemical concept of the gene, and therefore a decline in the interest in the molecular nature of the genetic material (Deichmann, 2004).

During the first half of the XX century, the main consensus in the scientific community about what could be the molecular nature of the genetic material responsible for the Mendel's Laws was that the genetic material was made of proteins (Deichmann, 2004). The chromosomal theory of inheritance established the chromosomes as the bearers of the mendelian factors. At that time proteins and DNA were already identified as the main components of the chromosome. Proteins were considered a complex compound capable of encoding genetic information, while DNA was considered a simpler compound, and therefore was not the first choice (Deichmann, 2004). Two experiments, though, brought the attention to the DNA as the bearer of the genetic information: first, the paper by Oswald Avery, Colin McLeod and Maclyn McCarty, where purified DNA was shown to be able to transform a non-virulent strain of pneumococcus into a virulent strain (Avery et al., 1944), and second, the paper by Alfred D. Hersey and Martha C. Chase, in which they demonstrated that DNA was responsible for multiplication of bacteriophages (Hershey \& CHASE, 1952). However, it was not only after the Watson and Crick's proposal of a structure for the DNA, that the DNA was widely accepted as the source of the genetic information (WATSON \& CRICK, 1953b; WATSON \& CRICK, 1953a). Watson and Crick's model gave a coherent explanation on how information was stored: a double helix, with twice the information, would allow the information to be stored, copied, and transmitted from one ancestor to its descendants. 
Although DNA was clearly accepted as the source of genetic information, it soon became clear that the specific phenotype of a cell was not only due to its DNA content. In parallel to all the development of the genetics field, the epigenetics field started to develop (Allis \& Jenuwein, 2016). Historically, the word "epigenetics" was used to describe events that could not be explained by the genetic principles. Waddington defined epigenetics as "the branch of biology which studies the causal interactions between genes and their products, which bring the phenotype into being" (WADDINGTON, 1942; Goldberg et al., 2007). Even before the Watson and Crick's model, some phenomena were clearly away from what it was expected just from the well-established genetic principles. As examples: position-effect variegation (MULLER \& Altenburg, 1930), transposable elements (McCLINTOCK, 1951), X-chromosome inactivation (LYON, 1961) and imprinting (McGrath \& Solter, 1984). Together with this, the concept of genomic equivalence made clear that the DNA sequence of a given cell was not the only factor governing the phenotype that a given cell shows (GURDON, 1962; GURDON et al., 1958).

Proteins were later shown, as well, to be able to transmit biological information from one organism to another. In 1982, the identification of a protein as the "Infectious Particle" in the scrapie disease, showed this (Prusiner, 1982). Strikingly, the problems that both, characterization of DNA as the "Transforming Principle" and prion proteins as "Infectious Particle" had, were similar. In both cases they had to prove the absence of the "opposite" component: proteins or DNA respectively (Prusiner \& McCarty, 2006).

Although, the previous example of prions as the "Infectious Particle" example, nowadays almost everybody identifies mainly biological information with the DNA. DNA is indeed synonymous of biological information. To be more precise, DNA is considered the source of the genetic information of an organism, and all the biological information that this organism has is thought to be derived from its own genetic information (with the rare exception of the well-known maternal effects characterized in Drosophila (Dobzhansky, 1935)).

Biological information could have many faces: from the DNA sequences itself, the RNA sequences, the protein sequences, the modifications of histone marks in a given histone tail, or the ordered response to a stimulus (external or internal) that generates a biological pathway, just to name some, but, since the fierce discussion about the molecular nature of the genetic information was clearly won by the DNA (WATSON \& CRICK, 1953b; WATSON \& CRICK, 1953a), we all see this cellular component as the ultimate source for all the biological information contained in a given living organisms. In other words: all the biological information of a given individual is ultimately dictated by the genetic information contained in its own DNA. This later statement is the hidden assumption that underline all the "Genome Wide Association Studies" (GWAS). Those studies try to find a relationship from the phenotypic characteristics of an individual and its own DNA sequence. 
The concept that all information contained in the DNA of an individual could give rise to all its phenotypic characteristics has its foundation in the central dogma of the molecular biology, as proposed by Crick 50 years ago (Crick, 1970) (from now on referred just as the central dogma). In recent years, the central dogma has been updated (Morange, 2009; Shapiro, 2009; Koonin, 2012; Koonin, 2015; Tan \& Anderson, 2020), but basically no change has been made in the role of DNA as the ultimate carrier of all heritable information passed on to new generations. In recent years, however, there has been increasing interest in transgenerational epigenetic inheritance in the scientific research community, increasing the focus on heritable information that is not transmitted through the genome, but through the epigenome (Lange \& Schneider, 2010; Prokopuk et al., 2015; Blake \& Watson, 2016; Xavier et al., 2019; Liberman et al., 2019; Duempelmann et al., 2020; Senaldi \& Smith-Raska, 2020). On top of that, the GWAS studies, mentioned before, are part of a central problem nowadays in biology: the missing heritability problem (Manolio et al., 2009). This problem goes into the heart of the concept of the transgenerational transmission of the biological information. Several solutions have been proposed for this problem, among them that the epigenome could be one possible answer for the missing heritability problem (Bourrat et al., 2017). In this paper I defend a complete recovery of the chromosomal theory of inheritance as a main framework for the understanding of how the biological information flows from one generation to the following ones. This means that both, the DNA and the proteins bound to that DNA (or modifications of that DNA; altogether known as the epigenome) do transfer biological information from the parental generations to the following ones. In fact, since the beginning of the questioning of where the biological information was physically stored, there has been a dispute between nucleic acids and proteins as the real agents of biological information. Therefore, it was considered that either DNA or proteins were the carriers of biological information. This fact assumes that if one of the two contenders won the battle the other has zero contribution to the heredity. But it could simply be that this dispute was, in fact, a human artificially created dispute (Marsellach, 2018).

In summary, the central dogma should be updated to include all new relevant findings, but specially to account for non-genetic generation-to-generation information transfer. To discuss all this I develop in the following sections an updated version of the central dogma with the focus on the epigenetic information and discuss the convenience to recover in full the chromosomal theory of inheritance to account for the intergenerational information flow. 


\section{The epigenome, the hereditary code that depends on the genome}

\section{but that is inherited per se separately from the genome.}

\section{The epigenetic code}

As explained above, the word "code" in biology leads mainly to think in DNA and the central dogma, and therefore to reduce the meaning of the word code to a sequence of either nucleotides (in the case of DNA and RNA) or sequence of amino acids (in the case of proteins). This is starting to be seen as a clear simplification, and many more codes are being recognized inside the biological world. Although ultimately all the information is encoded in the DNA sequence, the products of that code are needed to produce the decoding tools used to read the code (Tan \& Anderson, 2020; Jost, 2020). Therefore, the DNA alone is useless and needs from other components to be executed. Francis Crick's statement that there is no route to transfer back information from proteins to DNA is useful just when one thinks in the word "code" as "a sequence of", but it must be recognized that proteins do affect DNA function through other codes.

Epigenetics, like genetics started as an abstract concept with no idea of the mechanism that underlies them (Allis \& Jenuwein, 2016; Deichmann, 2004). As molecular biology developed, and epigenetic mechanisms were started to be known, it soon become clear that it represents a code for itself (Jenuwein \& Allis, 2001). The epigenetic code though is not as simple code as the genetic one (which can be reduced to "a sequence of") but a much more complicated one and that allow to store much more information on the same length of the DNA fibre (see Table 1 and Figure 1).

\begin{tabular}{|c|c|c|c|}
\hline & GENOME/TRANSCRIPTOME & EPIGENOME & \\
\hline \multirow[t]{3}{*}{ Decoding systems } & \multirow{3}{*}{$\begin{array}{l}\text { Transcriptional machinery } \\
\text { Translational machinery } \\
\text { RNA splicing and/or editing machinery } \\
\text {... }\end{array}$} & Histone based codes & $\begin{array}{l}\text { H3K4 } \\
\text { H3K9 } \\
\text { H3K14 } \\
\text { H3K27 } \\
\text { H3K29 } \\
\text { H3K122 } \\
\text { H4K20 } \\
\text { H2BK5 } \\
\ldots\end{array}$ \\
\hline & & DNA-methylation based codes & $\begin{array}{l}5 \mathrm{mC} \\
6 \mathrm{~mA} \\
4 \mathrm{mC} \\
\ldots\end{array}$ \\
\hline & & Non-coding RNA based codes & $\ldots$ \\
\hline Information container & $\begin{array}{l}\text { Sequence of nucleotides } \\
\ldots\end{array}$ & \multicolumn{2}{|c|}{$\begin{array}{l}\text { Coding component }+ \text { decoding partner } \\
\text { Position in the genome } \\
\text { Position in the nucleus } \\
\text { Other nearby epigenetic codes } \\
\ldots\end{array}$} \\
\hline Product & Proteins, non-coding RNAs, etc. & \multicolumn{2}{|c|}{ Epigenetically mediated cell functions, etc } \\
\hline
\end{tabular}

Table 1: Simplified comparison between the levels of complexity of the genome and the epigenome codes 
As an analogy, the use of an epigenetic code "on top" of a genetic code can be seen as a similar transition of the one that happened in computer programming with the introduction of objectoriented programming languages (OOP) compared to previous procedural programming languages (see Figure 2). As discussed earlier, even the simplest task to be done over the DNA needs from extra components to be executed. In this regard always there is feedback between the DNA and their products.

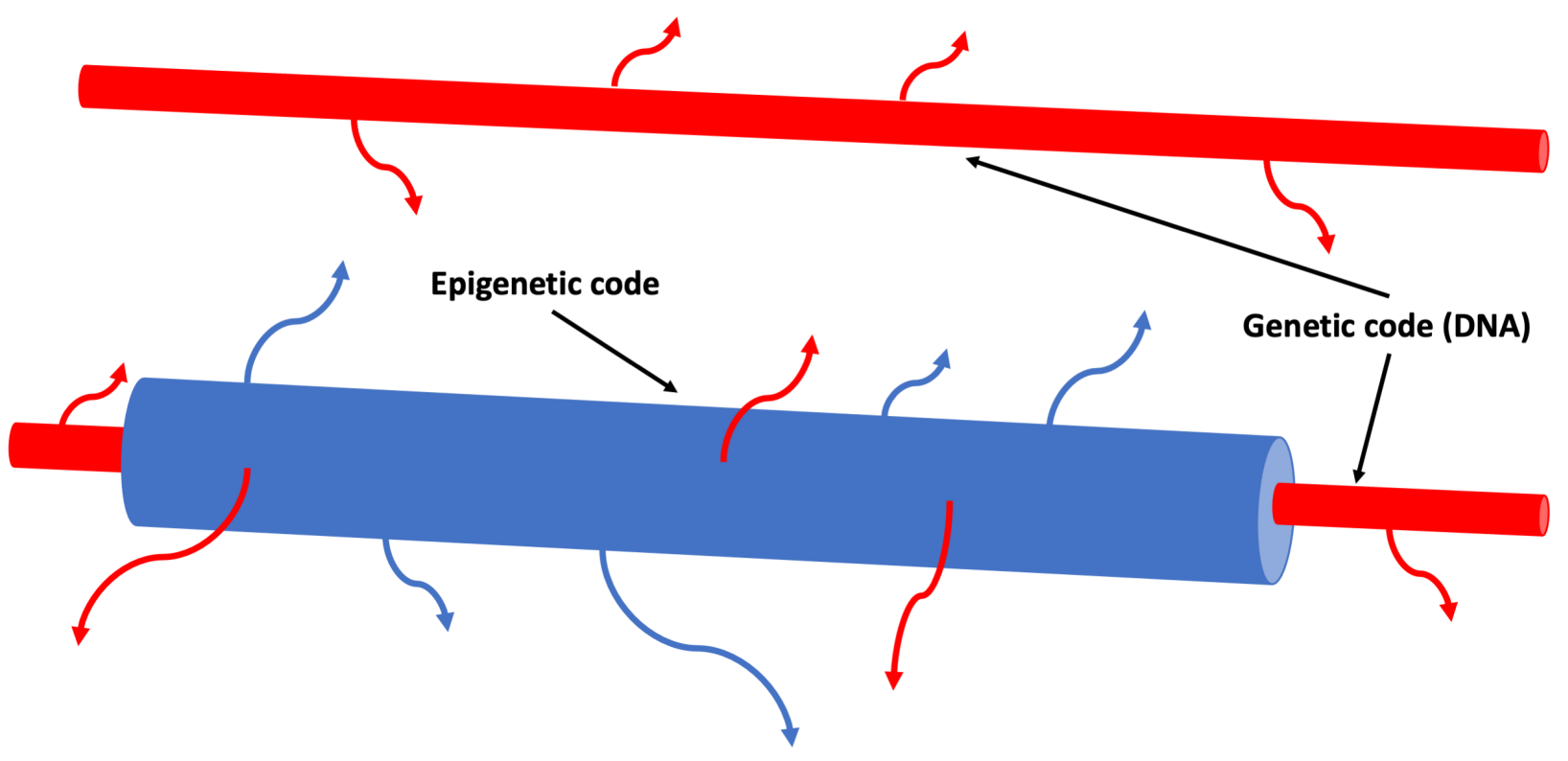

Figure 1: The Epigenetic Layer of Information. The epigenetic information adds an extra layer of information (blue cylinder) to the sequence information contained in the DNA (red cylinder). Arrows represent the exported functional information that comes from the DNA (red) or the epigenome (blue). Note that adding an additional layer of information "on top" of the DNA information allows more functional information to be stored for the same length of DNA fibre.

The existence of a dual code, the genome, and the epigenome, allows to achieve many more complex achievements. This has some parallelism with the OOP paradigm with allow many more complex achievements thanks to definitory aspects of the OOP paradigm like for example the code reuse. The analogy is not perfect as one can apply the class-object paradigm not only to DNA binding proteins (as plotted in Figure 2) but to the whole transcriptome and proteome. What makes the DNA binding factors (or to any biological component that affects DNA or biological components "on top" of the DNA) different from other players from the whole transcriptome or the whole proteome is that, by lying "on top" of the DNA fibre they create a new layer of "recorded" information that can be transmitted into the progeny and affect its phenotype. In this way, an individual inherits biological information through all the components of the chromosomes transmitted by their ancestors (not only through the DNA sequence). On top of that, the recorded epigenetic information is not only restricted to "a sequence of" but could be of many more types such as which kind of message contains (the concrete epigenetic modification), where it lies in the genome (on top of which concrete DNA sequence), or even how this affects the location of the DNA fibre inside the 3D structure of the nucleus, to name some (see Table 1). The fact that epigenetic 
information is recorded in ancestral chromosomes, and that those are transmitted independently from the DNA sequence (see below) is what gives to this extra layer of information a crucial importance in the intergenerational transfer of information.

In summary, the existence of a dual coding layer: the genome plus the epigenome creates richer information repository around the DNA: its coding sequence (the genome) and its associated factors (the epigenome); see Figure 1 and Figure 2.

\section{PROCEDURAL}
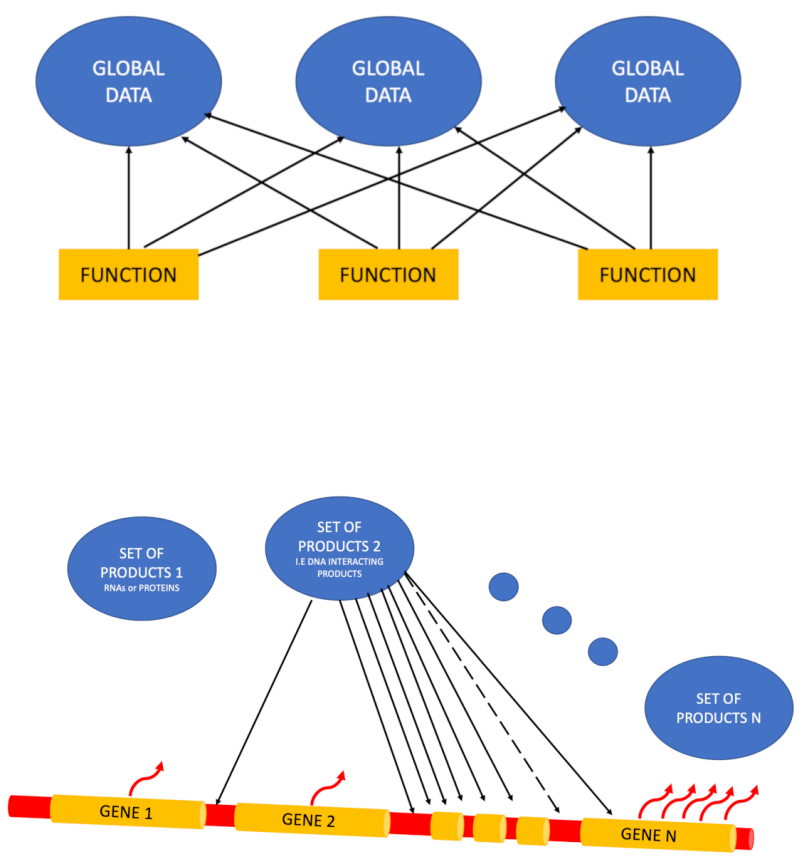

\section{OBJECT-ORIENTED}
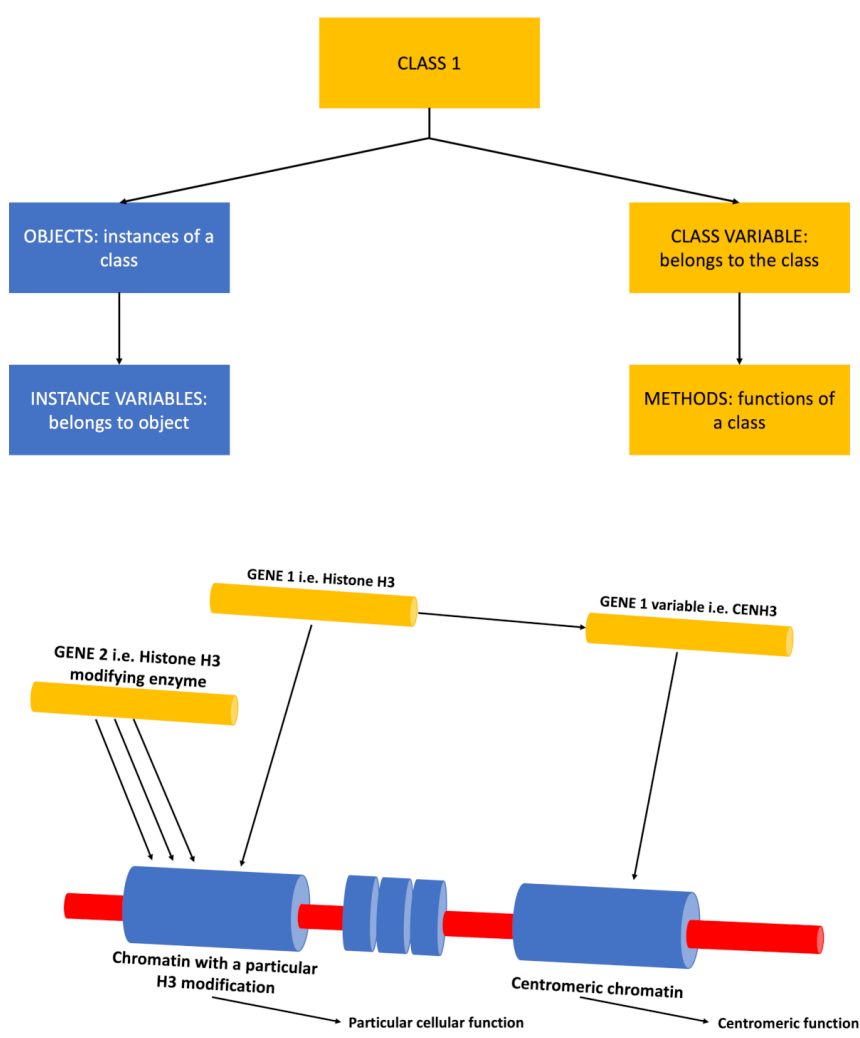

Figure 2: The OOP Epigenetic code. Comparison between the computer programming languages paradigms of procedural programming (left) and OOP programming (right). A schematization of the of both types of computer languages paradigms are plotted on the top part of the figure (top left: procedural programming schema; top right: OOP programming schema). A biological example is provided in the bottom part of the figure. Colour coding is used to reflect comparable elements. Note that, as describe in the main text, this proposal does

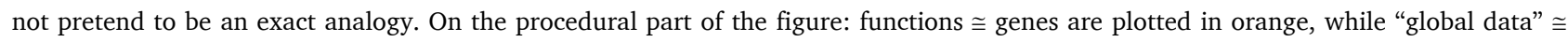
"genome products" are plotted in blue. In the OOP part of the figure: class $\cong$ gene are plotted in orange, while objects $\cong$ "epigenetic factors" are plotted in blue.

\section{An updated version of the central dogma}

In the Figure 3 I have plotted an updated version of the central dogma to account for the additional codes that exist inside biological information and that are not restricted to the genetic code as in the Crick's version of the central dogma (Crick, 1970). This proposal just wants to emphasize the existence of additional codes (especially the epigenetic ones) and does not pretend to be a final 
word in relation to the flow of biological information inside and between cells. As mentioned before some other proposals have already been made to update the central dogma.

A

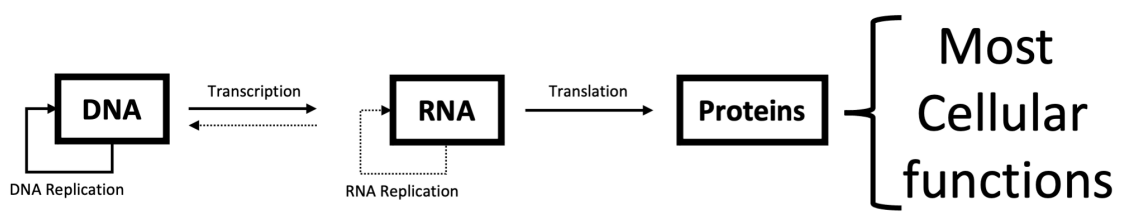

B

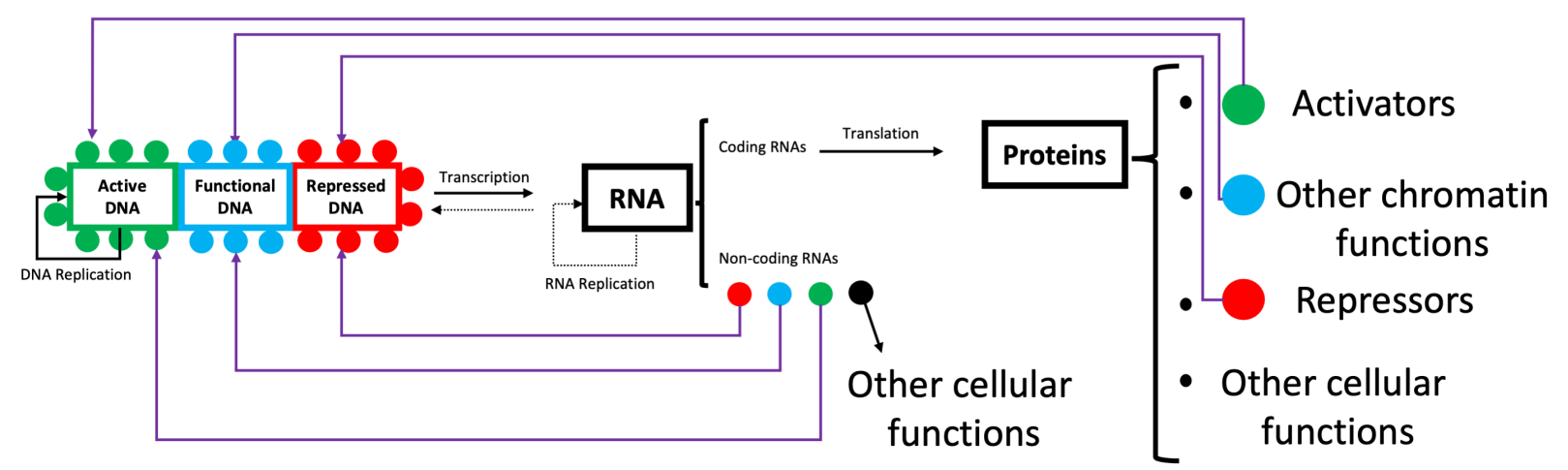

Figure 3: Central Dogma of molecular biology. (A) Classical schematisation of the Central Dogma of molecular biology proposed by Francis Crick (Crick, 1970). (B) A new schematisation of the Central Dogma of molecular biology which include the effect of epigenetic factors in the flow of information. Black lines stand for Watson-Crick based information. Solid lines stand for main pathways of information flow. Dotted lines stand for less frequent alternatives. DNA replication black line points only to active DNA for clarity purposes. Purple lines stand for epigenetically-coded information. For purpose of clarity a single colour was used, but as detailed in Table 1, many different epigenetic codes do exist. Epigenetic factors are arbitrarily divided in three colour coded categories: activators (green), other chromatin functions (blue) and repressors (red). This affects both proteins and non-coding RNAs, but it should not be limited to those components (there is no certainty that other kind of epigenetic components might exist). Adapted from Marsellach 2018 (Marsellach, 2018).

\section{Chromosomal theory of inheritance}

What the chromosomal theory of inheritance says is that the information that is passed from the parents to their offspring is the one contained in the chromosome, the whole chromosome. At the time it was formulated the term genetics did not even exist (Deichmann, 2004). Genetics started as a science in which an external observer, who has direct access to some phenotypical characteristics, tried to use them to deduce the underlying phenomena that can explain how they flow from one generation to the following ones. Later, with the birth of the molecular biology, the interest was not only in the heredity of those phenotypic characters, but on how they are mechanistically achieved. Genetically based characteristics (DNA based) were easily identified thanks to the work of Mendel and followers (Morgan, 1915; Bateson et al., 1902; Mendel, 1866). The beauty of Mendel's Laws and its astonishing correspondence with some early experimental observations made genetics a flourishing field with many successes. The discovery of the double strand structure of the DNA seemed to close the circle about how the biological information was passed from the parent to their 
descendants (WATSON \& CRICK, 1953b; WATSON \& CRICK, 1953a). Together with many more achievements in the molecular biology field this led to the concept of the central dogma and to almost identify the biological information uniquely with the information contained in the double helix of the DNA. This means genetic information almost became synonymous of biological information.

An external observer, however, has only access to the phenotypic information, with no a priori knowledge of the mechanisms by which this is achieved. A phenotypic characteristic that is only genetically-coded, will nicely follow the Laws of Mendel. This is easy to detect in the case of genetically-coded phenotypic characteristic coded in just one locus, but much more complicated for more complex genetic scenarios. To date, however, there is no accepted proposal of which pattern of inheritance one should expect for an epigenetically-coded phenotypic characteristic. In a previous manuscript (Marsellach, 2018), and in more detail in this paper, I propose a model to describe the intergenerational flow of epigenetic information from one generation to the following ones (see below).

I propose to recover the chromosomal theory of inheritance in full. This means that the biological information that the offspring get from their parents is the full information contained in the chromosome, the one contained in the DNA fibre (the genetic information) and the one contained in the factors and modifications that are linked to that genetic information (the epigenetic information). In the next section I discus about how the epigenetic information is handled during the meiotic and developmental processes that lead to a new generation.

\section{Flow of epigenetic information between a parental cell and its meiotically derived descendants.}

The study of the transmission of epigenetic information through the meiotic divisions is a hot topic in current research. Mammal studies showing full epigenetic erasure during gametogenesis and development prompted the view that almost no epigenetic information was transferred from parental cells to its meiotically derived descendants. Two main waves of epigenetic full reprograming have been described in mammals: 1 ) the gametic epigenetic reprograming (Hackett \& Surani, 2013; Cowley \& Oakey, 2012; Hill et al., 2018), and 2) the embryonic epigenetic reprograming (Smith et al., 2012; Kobayashi et al., 2012; Hirasawa et al., 2008; Kono et al., 2004). However, insights from recent studies suggest that there is not a complete erasure of previous generations epigenome, and so that the contribution of epigenetic information to the following generations seems to be something quite usual (Xavier et al., 2019). Indeed, evidence of transgenerational epigenetic inheritance is present not only in mammals, but in a wide variety of 
species ranging from yeast, plants, worms or mammals (Perez \& Lehner, 2018; Yu et al., 2018; Klosin et al., 2017; Miska \& Ferguson-Smith, 2016; Heard \& Martienssen, 2014; Becker \& Weigel, 2012; Greer et al., 2011; Grewal \& Klar, 1996).

This author has identified two main misconceptions in studies dealing with transgenerational epigenetic inheritance: first, some studies in higher organism use yeast data to compare or explain studies of transgenerational epigenetic inheritance without looking properly if those studies refer to mitotic or meiotic processes. Unicellular eukaryotic organisms like yeast can have descendants by both an asexual cycle (mitotic) or a sexual cycle (meiotic), but this is not the case in multicellular eukaryotic organism, where there is a differentiated type of cells in which those two processes happen separately (the somatic cells and the germline cells). In multicellular organism only the germline can transfer epigenetic information from then parents to the offspring. Examples of recent literature include cases in which meiotic epigenetic inheritance is referred as a known issue in yeast (Skvortsova et al., 2018) while citing yeast work dealing with mitotic epigenetic inheritance (Rusche et al., 2003). Meiotic epigenetic inheritance is certainly a known issue in yeast (Grewal \& Klar, 1996; Yu et al., 2018; Ragunathan et al., 2015; Recht et al., 2006), but the level of meiotic epigenetic inheritance characterization is not as high as the characterization of mitotic epigenetic inheritance in yeast (O'Kane \& Hyland, 2019); and second transgenerational epigenetic inheritance has led to a renaissance of Lamarckian-like evolutionary processes, which is still an open debate in the field of evolution and epigenetics (Koonin, 2014; Deichmann, 2016; Koonin \& Wolf, 2009; Loison, 2018; Danchin et al., 2019; Jablonka \& Lamb, 1995; Jablonka \& Lamb, 2020). A Lamarckian view of transgenerational epigenetic inheritance implies that the biological information acquired by the parents is transmitted to the progeny, and so, anything that leads to an erasure of previously accumulated epigenetic information is seen as a loss of information event. This view implies that the reprogramming processes happening in mammal's gametogenesis and development are a loss of information events. However, this is not at all true. For a given epigenetic mark to accomplish its function it must be present when this is needed (in timely manner). A given epigenetic marks (or enzymes that builds them), needs to be expressed at certain cellular types and/or in certain developmental processes. If a particular epigenetic mark is lost, after the host cell has lost the ability to re-create it, then an epimutation is generated (Marsellach, 2017). Therefore, the reprogramming processes happening during meiosis or developmental processes are in fact a gain of information process like the ones happening in the cell differentiation processes (see Figure 4). In summary, in both cases, reprogramming and cell differentiation, the right epigenetic information is put in the right place at the right time. Reprogramming (rejuvenation in fact) is nothing else but and specialized form of cell differentiation that puts the previous epigenetic information in place (the young epigenetic information according to the model proposed in this paper). 
A

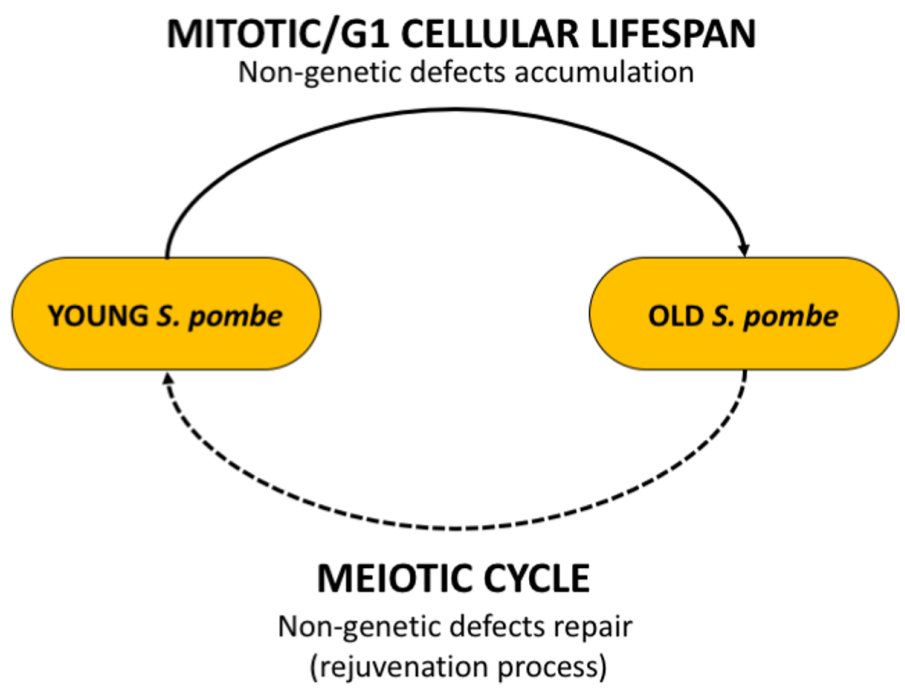

B

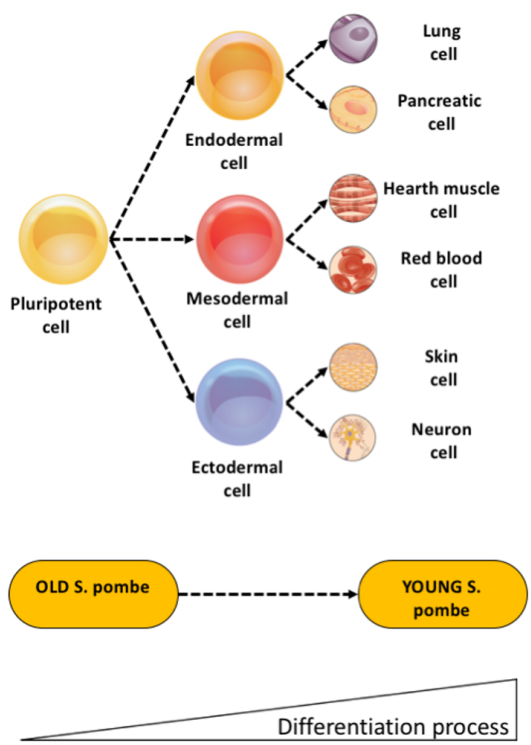

Figure 4: Cyclical, differentiation-like nature of the ageing process. (A) Schematic representation on how a simple cyclical process, with two different phases, can allow explaining the ageing process: 1) the mitotic/G1 phase (top), in which non-genetic defects are accumulated; and 2) a meiotic phase (bottom), in which non-genetic defects are specifically repaired. The non-continuous line in the meiotic process indicates that, in most cases, this process did not go back to the same individual cell, but to its next generation. $S$. pombe is used as an example of an organism affected by ageing. (B) Schematic representation of how the rejuvenation process can be understood as a specialized differentiation process. Adapted from (Marsellach, 2017).

\section{The Laws of Mendel, Schrödinger's cat-like interpreted}

Not all the approaches to transgenerational epigenetic inheritance deal with the problem with a Lamarckian biased approach. I have previously proposed a non-Lamarckian model for the inheritance of epigenetically coded characteristics (Marsellach, 2018) that is further developed in this manuscript (see below). The epigenetic reprogramming is thought to be a process that corrects epigenetic errors accumulated in previous generations (Reik, 2007; Faulk \& Dolinoy, 2011; Chen et al., 2006; Bruno et al., 2015; de Waal et al., 2012; McCarrey, 2014; Marsellach, 2017). This is the foundation of the model that I propose. During the epigenetic reprogramming there is a rewriting of information and a repair of accumulated epigenetic mistakes (or epimutations). In most cases, the right information is put on place (i.e., the newly functional information is written at the right place, and the accumulated epimutations are corrected), but eventually some of them might be overlooked and passes on to subsequent generations. This leads to transgenerational epigenetic inheritance (in the case of non-corrected epimutations) or newly acquired defects (in the case of failure into put the newly functional information into the right place). According to this model two kind of epigenetic defects would be transferred to newly born individuals: 1) previously not repaired epimutations (Figure 5B), and/or 2) newly generated epimutations (Figure 5C). The lack of repair/deposition of some epiloci could be due to a limitation of resources (or time) to rewrite all of them, which would lead to a scenario where a certain number of mistakes would be passed to the 
newly born generations. This happens randomly. In accordance with this, it is predicted that, in cells with lots of epimutations a higher number of them would not be repaired; and, at the same time, in the other way around in cells with few epimutations it is more likely that all of them are repaired (Marsellach, 2018).

In an ideal scenario a cell with few epimutations entering meiosis would have most of them repaired/rewritten. Therefore, for the phenotypic characteristic, coded by those particular epigenetic factors a non-Mendelian ratio will be observed (see Figure 5B left and middle panels, and $5 \mathrm{C}$ left panel). However, if a cell with lots of epimutations do enter meiosis, then, in some given epimutations repair would not happen and/or newly generated epigenetic defects would be passed to the new generations. For the phenotypic characteristics coded by these given epiloci a mixture of Mendelian and non-Mendelian ratios will be observed (see Figure 5B right panel and 5C three rightmost panels). 
A

\section{GENETIC INFORMATION}

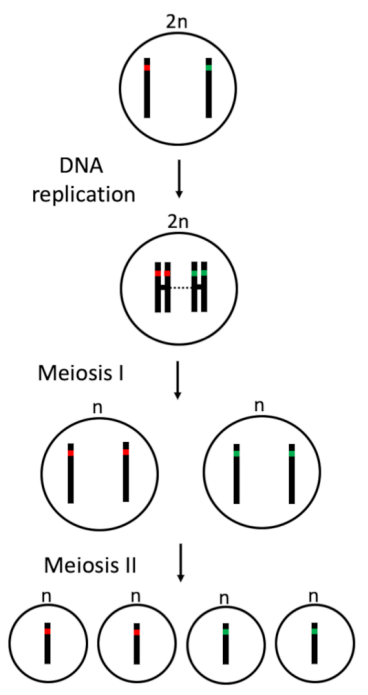

2:2 = Mendelian segregation
B

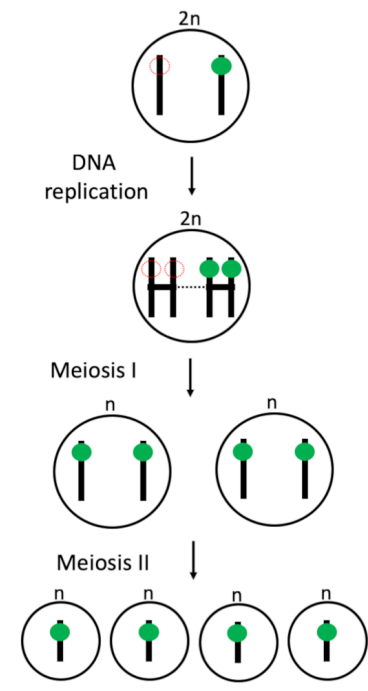

4:0 = DO NOT TRUST MENDEL
EPIGENETIC INFORMATION CORRECTION

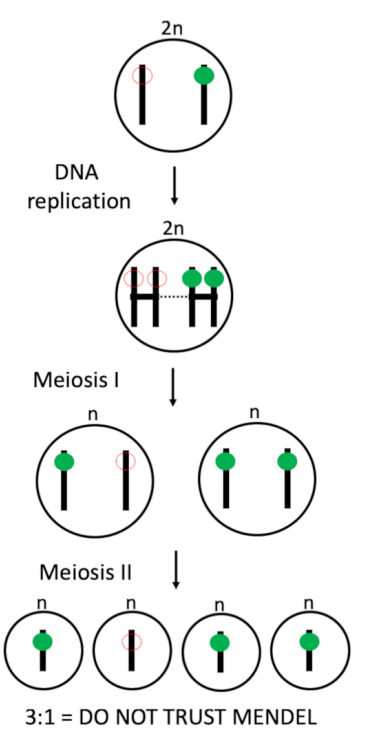

NEW EPIGENETIC INFORMATION DEPOSITION

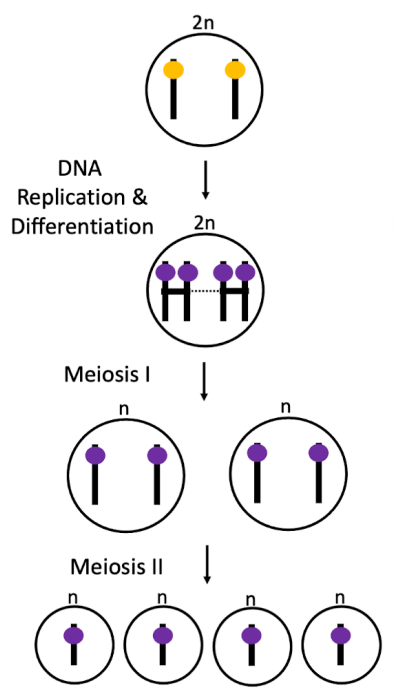

4:0 = DO NOT TRUST MENDEL
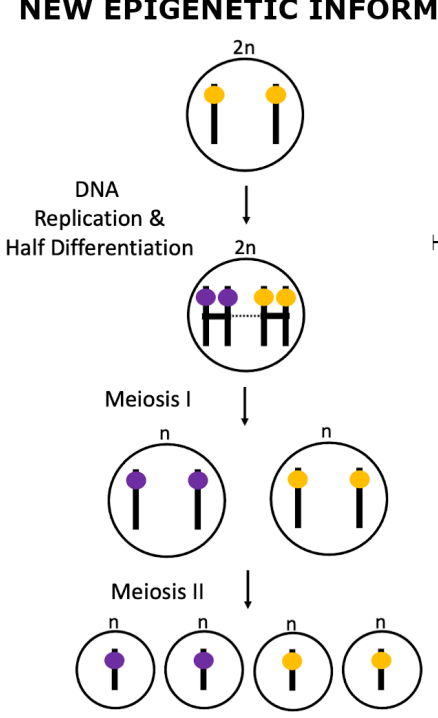

$2: 2=$ TRUST MENDEL
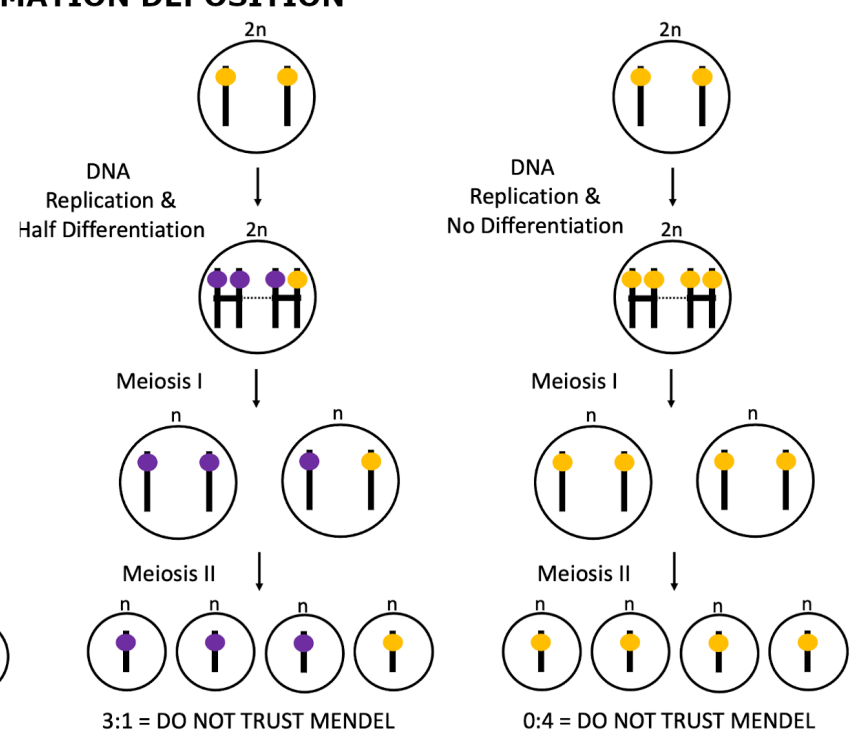

Figure 5. Schrödinger's cat-like Laws of Mendel for the segregation of the epigenetic information. Schematic representation of a several meiotic processes. (A) the Laws of Mendel governing the segregation of the genetic alleles. (B) Three panels to outline the segregation of epigenetic alleles according to a repair/not-repair scenario. In the examples showing the segregation of those epialleles, three scenarios are contemplated: 1) Full meiotic repair (left panel), 2) half meiotic repair (middle panel), and 3) no meiotic repair (right panel), of a given epiallele. (C) Four panels to outline the segregation of epigenetic alleles according to writing/not-writing of newly deposited information. In the examples showing the segregation of those epialleles, four scenarios are contemplated: 1) Full differentiation (left panel), 2) and 3) half differentiation (middle panels), and 4) incorrect differentiation (right panel). Cells are represented as big circles, one pair of independent solid black lines inside those circles represents one pair of homologous chromosomes (just one pair for simplification purposes). Sister chromatids, once DNA has been replicated, are plotted as joined solid black lines. Pairs of homologous chromosomes are joined by a dotted black line. Genetic DNA alleles are represented as red (defective) or green (wild type) dots, inside the solid black lines (to show that they are part of the DNA fibre). Epigenetic factors are plotted as small, coloured circles (green, yellow or purple). The absence of a given epigenetic factor in one locus are plotted as red dotted circle lines instead of the epigenetic factor. Epialleles are plotted on top of the solid black line (the chromosome), to show that they do not strictly form part of the DNA fibre. In (B), two scenarios are contemplated for a meiotic epigenetic repair: full meiotic epigenetic repair (left panel), and half meiotic epigenetic repair (middle panel). This is done to contemplate all theoretically possible scenarios. In (C) old epigenetic marks are plotted as yellow circles, while newly incorporated epialleles are plotted as purple circles. For the middle panels picturing a half differentiation process two different scenarios are contemplated. Adapted from Marsellach 2018 (Marsellach, 2018).

As seen in Figure 5 this leads to a Schrödinger's cat-like scenario when an external observer analyses the pattern followed by an epigenetically-coded phenotypic characteristic (see Figure 5). In 
comparison with the nice and easy Mendelian ratios followed by genetically-coded phenotypic characteristics (see Figure 5A). The model that I am presenting it simply implies that epigenetically inherited characters have a similar inheritance to the well-known maternal effects characterized in Drosophila (Dobzhansky, 1935), but with maternal and paternal contribution (Marsellach, 2018).

In summary, the randomness nature of the epigenetic repair/rewriting program happening in all meiotic cells might lead to a Schrödinger's cat-like scenario when studying the segregation of the phenotypic characteristics coded by epigenetic factors.

\section{Life and ageing as information-based phenomena.}

\section{The model}

As detailed earlier, an increasing interest in ageing and epigenetics has recently appeared in the scientific research community. Ageing has been traditionally linked to damage, as if it was a wear and tear phenomenon. Recently, some works have proposed epigenetics as a unique cause of ageing (Chiavellini et al., 2021; Ashapkin et al., 2017; Marsellach, 2017; López-León \& Goya, 2017; Ocampo et al., 2016; Gibbs, 2014), but a formal probe of that is still missing. Below I propose a testable model that could help solve the epigenetic nature of the ageing process, and, at the same time, give a coherent description of what life is.

I propose to conceive life and ageing solely as information-based phenomena, this has already been done previously, but separately: for life (Krakauer et al., 2020; Jost, 2020; Adami, 2012), and for ageing (Yang et al., 2021; Sinclair \& LaPlante, 2019; Marsellach, 2017; Marsellach, 2018). According to my proposal, though, live and ageing are indeed two sides of the same coin, and so equal approaches should be used to study them. Below I propose ways to put under test the epigenetic nature of the ageing process. Those experiments could serve as well to reinforce the linkage between ageing and life due its shared nature based on information.

Life is a continuous use of the biological information to overcome the extrinsic or intrinsic factors that prevents biological information from still being useful for its maintenance "purpose". Ageing is a random or programmed (see below) temporary loss of epigenetic information that creates an intrinsic factor preventing the biological information from being useful. Ageing of a given individual is therefore a half-cyclical process, that although ends with its own death, allows the continuity of life thanks to a full cyclical reuse of biological information that this individual transfer to its 
descendants (see Figure 4A, and Figure 6). Previous proposals of ageing as a loss of epigenetic information have been made (Yang et al., 2021; Sinclair \& LaPlante, 2019; Marsellach, 2017; Marsellach, 2018).

This proposal has two unproven premises: first to conceive the ageing process as a loss of epigenetic information process. The epigenetic information inherited from the meiotically derived parental cells have the right information to produce a young phenotype. During the lifespan of a multicellular organism both the soma and the germline change their epigenetic marks due to developmental processes and accumulated epimutations. The somatic cells will never read again the relevant epigenetic information for achieving a young phenotype (the "young epigenome"), while the germline cells will do so when producing the following generation. In the germline the relevant information to restart the developmental process is read again, and the accumulated epimutations of previous generations are repaired. In summary, the relevant epigenetic information is put in the right place to achieve a "young epigenome". A second premise of the proposed model is that the difference between these two scenarios is to continue alive (in the germline by receiving the appropriate functional information) or to die (in the soma due to a lack of adequate functional information due to loss of epigenetic information and the accumulation of epimutations). This later premise implies that lethality due to intrinsic factors is mainly epigenetically caused (see below).

The conception of life that I propose looks like a nonsense from a human individual perspective: the soma accumulates epimutations that know how to repair, germline does it to create the new generations that would overcome us, but somatic cells do not do it because the tools for doing so are simply not used in those cells. According to the model, this has a severe consequence: death of the somatic cells (and germline cells not emancipated from the organism). Why could this happen? Why dying if you have the right information for not to do it. The answer to this question is that this simply works to allow life continuity and acquisition of further complexity (see below).

\section{The emergence of the phenomenon of ageing}

As discussed earlier, there is no consensus on when and why ageing arose (see above). I propose that ageing arose due to the appearance of epigenetic information and the complexity increase that this allowed. I propose that this is the case given that there is a trade-off between the complexity of the lifestyle and the lifespan than an organism can have due to extrinsic mortality causes.

\section{Trade-off between complexity lifestyle and lifespan}

The less complex your lifestyle, the less likely you are to die from an extrinsic factor and therefore you are more able to "afford" a long lifespan. The opposite is as well true, the more complex your 
lifestyle, the more chances to die from am extrinsic factor and therefore having biological mechanism that provide you a long lifespan would not increase your chances to live longer.

As detailed in the sections above, the acquisition of an epigenetic code during evolution might have allowed to achieve much more complex biological structures (there is more information available and more ways to bring this information into functional outcomes). Therefore, the more complexity was accumulated during evolution through the epigenetic code, the more complex lifestyles were developed. This had as a side effect the increase of chances of dying due to extrinsic factors (and therefore not to keep transferring the accumulated information to the offspring). The complexitylifespan trade-off due to extrinsic mortality causes might had reached a point in which a further complexity acquisition did not increase the chances to keep storing new information (complexitylifespan trade-off limit; see Figure 6A). In other words, if an amortal organism with a complex lifestyle has ever appeared during evolution, it might have gone extinct because the chances of dying by extrinsic factors would probably have been higher than the advantages that amortality provides. In consequence, all organism above a certain level of complexity would probably die due to extrinsic factors and therefore not contribute further to the pool of living organism and neither to the pool of accumulated information.

\section{The appearance of sexual reproduction: the mastering of ageing.}

The observation of ageing-like behaviours in prokaryotic cells (Ackermann et al., 2007) opened the debate on when ageing arose. Before it was assumed that ageing appeared after the origin of eukaryotic cells. I propose that, although ageing was not an all or nothing transition from one day to another, the appearance of the eukaryotic cells meant a mastering of the ageing process, and therefore, one can trace back the origin of a full ageing-era into the origin of the eukaryotic cells. However, there was (and there is already) a pre-full-ageing era in which ageing like phenomena was (are) observed in procaryotic organisms. In this sense non-eukaryotic cells are still trapped in a pre-full-ageing era (see Figure 6).

DNA alone (genetic material) is useless without non-genetic material that decodes it. A slow increase in the acquisition of non-genetic information and the use of it, allowed a further complexity increase, but at the same time created a need to maintain both the correct genetic information and the correct non-genetic information to maintain properly working conditions (homeostasis).

However, with the appearance of eukaryotic organism and sexual reproduction (Speijer et al., 2015) an incipient distinction between the soma and the germline was created. The key aspect is the acquisition of a meiotic division. The meiotic division allowed to achieve a soma-germline distinction inside a single cell (in unicellular organism). This was achieved by separating in time 
two kind of cell divisions: the mitotic division (which did not lead to a sexual cycle; this is the ancestral division) and the meiotic divisions (which led to a sexual cycle, the newly achieved mechanism). This incipient distinction between the soma and the germline created two different paths: the path of irremediable epigenetic information loss (in the soma-like cells) which eventually leads to death, this is the ancestral scenario; and the path of epigenetic information recovery (in the germline-like cells), the newly create scenario to allow to maintain the continuity of life across several generations although earlier born individuals died due to extrinsic factors (environmental factors) or intrinsic factors (loss of useful information needed to keep the correct functional homeostasis or overcome lethal environmental barriers, in other words: ageing).

The eukaryotic cell, however, is not only characterized by the meiotic division, but by the presence of a nuclear compartment, isolated from the cytoplasm which contains the genetic, and epigenetic information. The appearance of a cellular membrane allowed a structural compartmentalization of the biological information (genetic and epigenetic) that itself is part of the epigenetic information (see Table 1). In this sense, the eukaryotic cells mastered the ageing process, by creating the meiotic step (which implies a recovery of the epigenetic information, see below), and by acquiring a nuclear membrane that allowed a further usability of the epigenetic information.

The incipient distinction between soma and germline was further increased with the appearance of multicellular organism. In the next section I propose how this allowed to accommodate the ageing phenomenon without harming the continuity of life.

\section{Life as a continuity in the face of ageing phenomenon.}

To analyse the pathways that allow life as a continuity in this new scenario one has to differentiate between unicellular and multicellular organism.

1) Unicellular organism:

Unicellular organisms divide by mitosis (prokaryotes) or by mitosis and meiosis (eukaryotes), those organisms though, are far less complex than multicellular organism which needs from a developmental process to be shaped. The multicellular organism therefore needs much more information (either genetic or epigenetic) for its proper development and function than unicellular organism. A process of epigenetic information loss (as the ageing process is proposed to be in this essay) would then be affected by how many epigenetic information the organism has and how and for what is this information used for. In other words, ageing should be affected by the functions that the organism must achieve via its epigenetic information. 
A

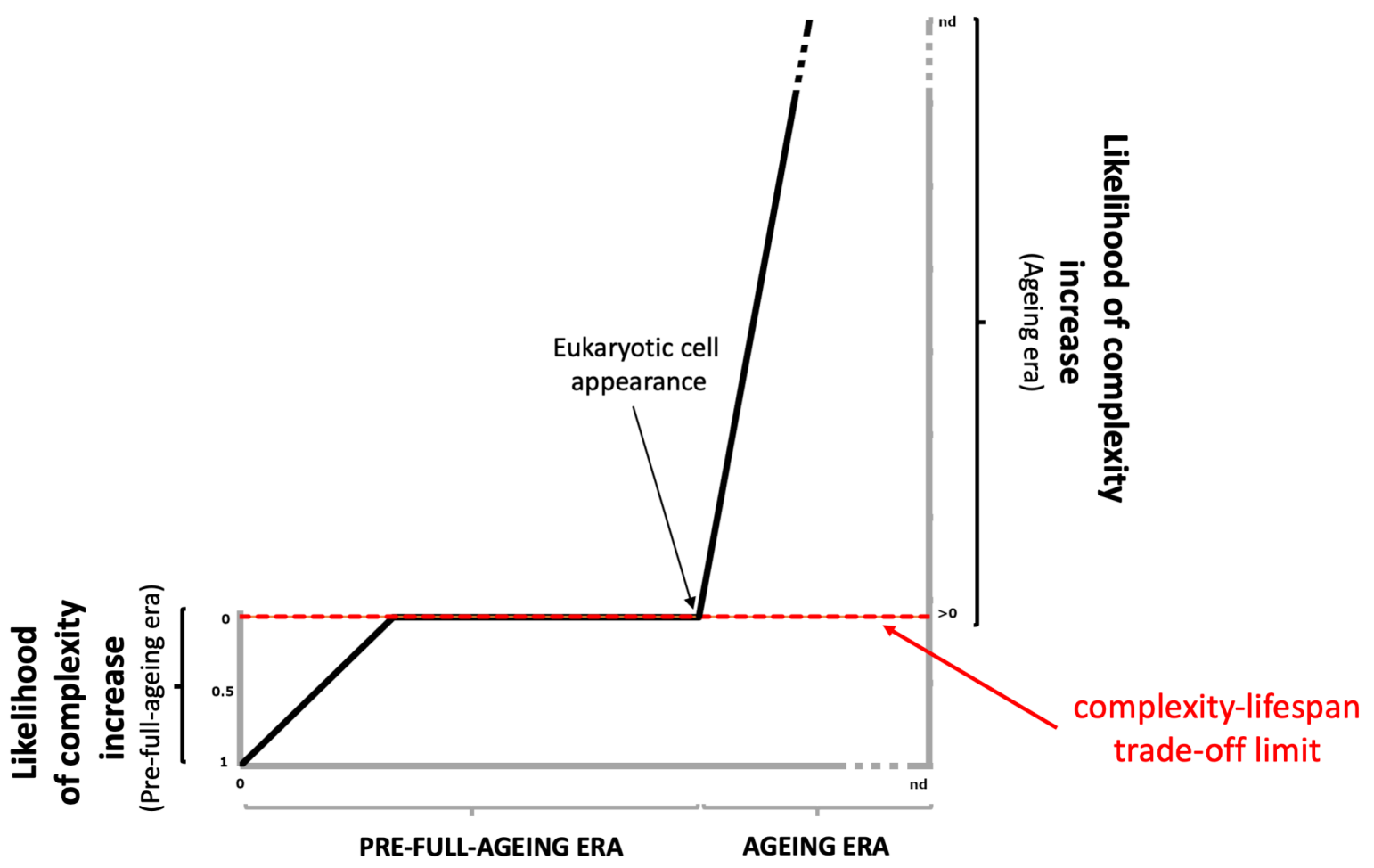

TIME

B

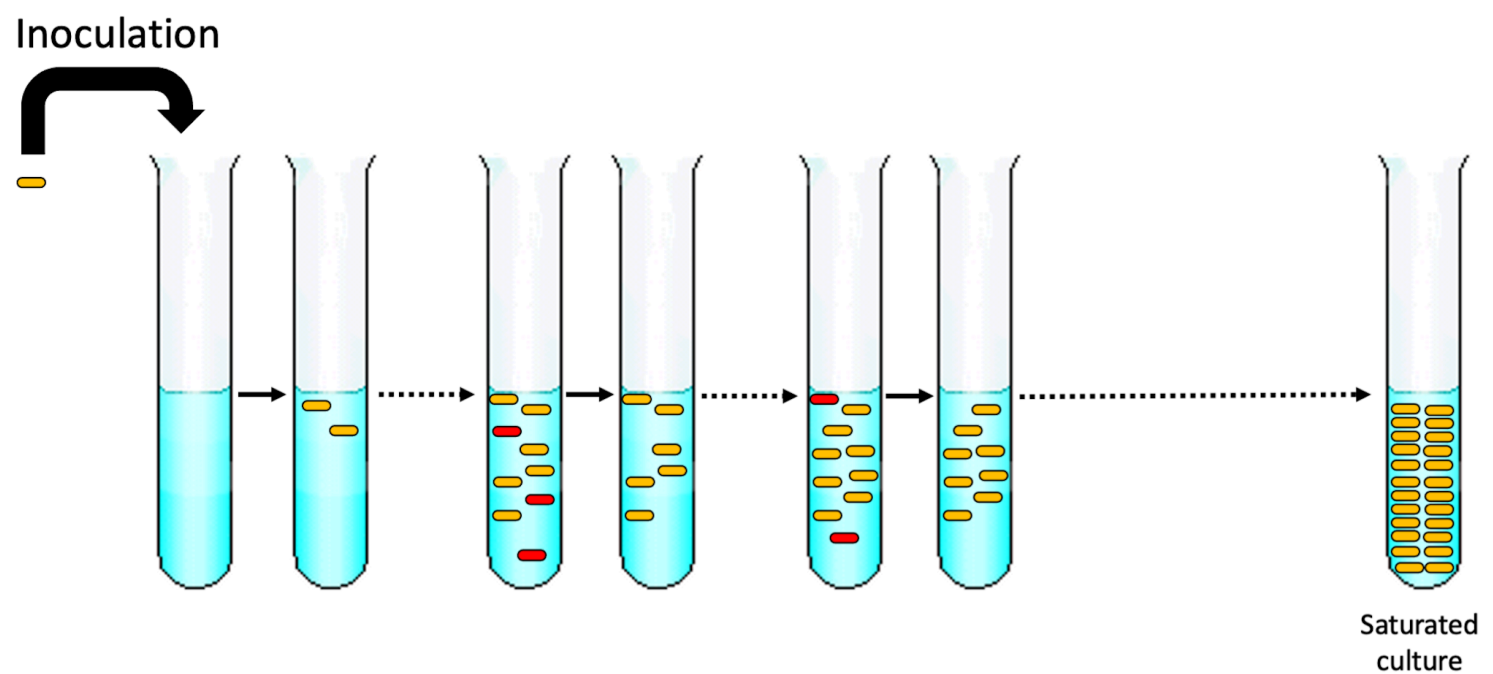

C

Time

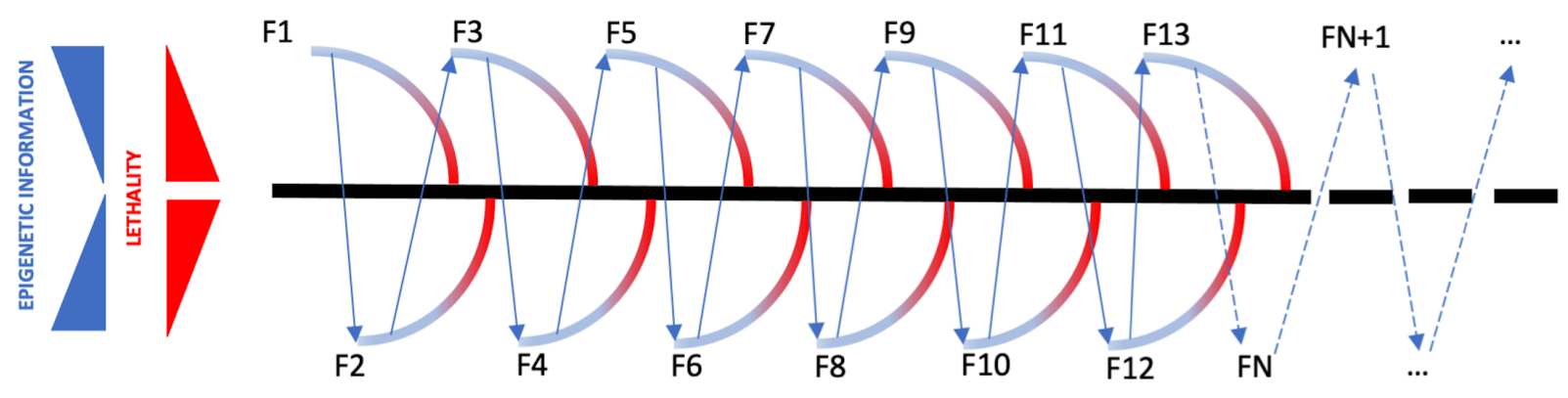


Figure 6. Complexity-lifespan trade-off and lethality avoidance strategies. (A) Complexity-lifespan trade-off schematization. Likelihood of complexity increase is represented with respect to time. During pre-full-ageing era (left axis) this likelihood reached the value of zero due to increased chances of extrinsic death as complexity increases. In full ageing era (right axis) the mastering of ageing in eukaryotic cells (cyclical reuse of epigenetic information) allowed a further increase in complexity acquisition despite further increases in extrinsic lethality. In both cases a linear increase is plotted for simplicity purposes. No value (other than $>0$ ) is plotted at the starting of the ageing era as formal quantification of those phenomena is out of the scope of this paper. Complexitylifespan trade-off limit line is plotted in red dotted line. (B) and (C), Lethality avoidance strategies of unicellular (B) or multicellular (C) organism. (B) An example of grow of unicellular organism in laboratory test tubes is shown. Epi-wild-type individuals are plotted in orange, while epimutants are plotted in red. (C) A schematization of the overlapping generation mechanism of lethality avoidance used by multicellular organism. Individual lifespans are plotted in quadrants shaped gradients that evolve from blue (epiwild-type) to red (epimutants) organism. Lethality of epimutants occurs when they reach the temporal black line. Blue arrow represents transgenerational information transfer that gives an epigenetic young phenotype (epi-wild-type) to newer generations. This figure was, in some parts, adapted from the "Test tube true C.png" file created by Theresa Knott and obtained via Wikimedia Commons.

Unicellular organisms do not have complex developmental processes in their life cycle and use mainly epigenetic processes to deal with environmental changes (i.e., to switch from a nutrient rich media to a nutrient poor or and stressful media (López-Maury et al., 2008)). Epigenetics does not describe a developmental program as it does in multicellular organism. In this scenario, epigenetic information loss, and therefore the ageing process, might be reduced mainly to a random accumulation of epimutations.

Unicellular organism (prokaryotic or eukaryotic) does not need for a complex system to maintain the continuity of life thanks to their ability to produce millions of identical copies of themselves (generated by mitosis). Among all those copies, the ones that have less epimutations accumulated (by chance) will overgrow the more epimutated ones (see Figure 6B).

In prokaryotic organisms life could be maintained by a continuous reading of the genetic information that allows to replace the eventually lost epigenetic information. This is the situation defined above as pre-full-ageing era. Death by loss of epigenetic information could happen in this scenario by a quicker rate of information loss compared with the rate of information recovery. In summary: unicellular procaryotes, like bacteria and archaea, are probably still trapped in a pre-fullageing era where viability is maintained by a more or least constant reading of the relevant information for survival (no distinction between soma and germline) and for the ability to quickly produce millions of descendants from just one single organism (see Figure 6B).

In eukaryotic organisms though, the sexual reproduction creates a clear distinction on when the information is lost (mitotic division, soma-like scenario) or when the information is recovered (meiotic division, germline-like scenario). Unicellular eukaryotes, thanks to their null or relatively simple developmental process, are still able to maintain randomly the correct epigenetic information thanks to their ability to produce millions of descendants from themselves (see Figure $6 \mathrm{~B})$. It should be noted that, the conditions in which for example yeast is grown in the laboratory, is far from the scenario that they find in the nature. It is probable then, that although they are able to grow for many generations under mitotic cycles in the rich media used in labs, in the nature they require a frequent passage through a sexual cycle for a prolongate survival. It should be noted as 
well that some unicellular eukaryotic organism like yeast (highly used in ageing research) are indeed simplified multicellular organisms (Kiss et al., 2019), and so they live in between two worlds: are able to survive through the production of millions of identical copies of themselves (as prokaryotes do) and might be affected by the more program-like scenario of ageing in multicellular organisms (see below). In summary: unicellular eukaryotes are in a full-ageing era, but still retain mechanism from the pre-full-ageing era to maintain the continuity of life.

2) Multicellular organism

Multicellular organisms have at least one program to follow: the development from the zygote to the newborns organisms. On top of that epigenetic information might regulate further developmental stages after birth. This requires a higher use of epigenetic information than in unicellular organisms for bringing the biological information (genetic plus epigenetic) into a phenotype outcome. In multicellular organisms the strategy of producing millions of descendants is not useful, or simply less useful and less useful with every bit on increase in complexity. Newer lethality avoidance strategies had to be developed to avoid extinction. Conceiving ageing as a loss of epigenetic information phenomenon allows an envisage an easy solution for this problem: overlapping generations of mortal individuals (see Figure 6C). The full distinction between the soma and the germline allowed the appearance of a specific program to rewrite the epigenetic information in the germline so the functional information is recovered and passed to a newborns individuals, which not only starts its existence with the youngest epigenetic information, but as well with its chances of dying by extrinsic factors reset to zero. Before its "conception" this organism didn't even exist. Neither did its chances of dying by an extrinsic factor, Importantly, even with a high ratio of newborns lethality, the production of a high number of descendants, might allow to achieve a continuity in life by overlapping generations of mortal individuals. In summary, by overlapping generations of mortal individuals, the full development of the ageing process allowed to overcome the limitation of complexity acquisition due to extrinsic lethality factors (see Figure 6A and 6C), and to keep accumulating and storing genetic and epigenetic information that allow a further increase in complexity beyond the limit given by the complexity-lifespan trade-off limit (see above).

In multicellular organisms, the epigenetic information is not only used in gametogenic (meiotic) and/or developmental processes, but by many processes through all the lifespan of the organism. In this sense ageing, understood as a loss of epigenetic information process, might be affected by all those processes making that, in multicellular organisms, ageing is probably more a program-like process than a random-like process. In fact, it is probably a mixture of both: a program-like process and a random-like process (environmentally affected). 


\section{Summary:}

Altogether in all scenarios (unicellular or multicellular organism) according to the model presented in this paper, ageing is a consequence on how information is handled during vegetative grow and during the meiosis (and subsequent steps). During vegetative growth the epigenetic information is lost, while during processed happening in germline derived cells the relevant epigenetic information is read and used to create a young newborns organisms. Ageing is therefore merely a consequence of how epigenetically coded information is inherited. From a conscious perspective, ageing is the price that we complex organism, pay for being complex (all our ancestors paid their bills, we just keep doing so).

\section{The present and potential experimental evidence for the proposed}

\section{model}

The above proposed model is so far a speculation based in two premises (see above). In this section I summarize the experimental evidence already obtained to support this model, as well as I list some easy-to-check experimental frameworks that could help clarify whether the proposed model is accurate or not.

\section{Experimental observations in accordance with the proposed model}

The ageing field is starting to be hit by an epigenetic reprograming revolution. Through epigenetic reprograming some never before thought achievements are being accomplished, mainly by ectopically inducing reprograming via the four Yamanaka factors: Oct4, Sox2, Klf4 and c-Myc (OSKM) (Takahashi \& Yamanaka, 2006). From resetting ageing hallmarks of cells from centenarian individuals (Lapasset et al., 2011) to ameliorating age associated hallmarks in aged organism in vivo (Ocampo et al., 2016; Sarkar et al., 2020; Rodríguez-Matellán et al., 2020; Lu et al., 2020). All these new scenarios are difficult to explain with most of the long-time proposed models of ageing, especially the damage-based models of ageing, but are very easily explainable by the model presented in this paper: ageing as an epigenetic information-based phenomenon and epigenetic reprograming as a regain access to an always kept information. This information is never read again in somatic cells but read again during meiotic and developmental processes that start from germline cells to give rise to the newer generations. Ectopic reading of the relevant information can be induced ectopically in somatic cells by cell reprograming strategies (Takahashi \& Yamanaka, 2006), leading to a rejuvenation of markers of ageing in those cells (Horvath, 2013). In physiological conditions though this reading of relevant information only happens in germline derived cells. 
These great achievements have been preceded by almost a decade of increasing involvement of epigenetic processes in ageing (Zhang et al., 2020). This includes, among many more studies, the thriving field of epigenetic clock development (Liu et al., 2020; Ryan, 2020; Bell et al., 2019; Horvath, 2013; Bocklandt et al., 2011), and its relationship to all-cause mortality in humans (McCrory et al., 2020; Marioni et al., 2015). The relation between all-cause mortality and epigenetic clock signature suggests a somehow epigenetically caused mortality, as predicted by the model described in this paper. According to the model, lethality is mainly epigenetically caused and the end of the further flow of information (which, as proposed, describes life).

Altogether all these studies relating epigenetics and ageing favours an information-based conception of ageing rather than a damage-based conception of ageing. It has already been shown that modifying the epigenome (through reprograming) does reduce the impact of damage accumulated to the cells (Sarkar et al., 2020; Lu et al., 2020). This directly suggest that damage is not the cause of ageing but one of its consequences.

Another observation that is difficult to accommodate in a damage-based conception of ageing is the fact that Hutchinson-Gilford progeria syndrome (HGPS) is caused by a single point mutation in the Lamin A gene (Wang et al., 2020; Eriksson et al., 2003).This observation is difficult to explain in a damage-based conception of ageing, where damage accumulation occurs during lifespan due to changes into balance between damage generation and damage repair, and the consequent accumulation of damage that this implies all along the lifespan of the organism. Could all these complex mechanisms be caused by a point mutation? An information-based conception of ageing offers a more parsimonious explanation for such observation. As proposed, eukaryotic cells mastered the ageing process that had already begun in prokaryotic cells. The Lamin A protein is an integral part of the nuclear membrane, and by lying there could contribute to the spatial organization of the chromatin, that as proposed, could be an epigenetic information container (see Table 1). A single point mutation in Lamin A protein could therefore imply a sudden disorganization of nuclear architecture, characteristics that has been shown to happen in ageing and to HGPS affected cells (Cenni et al., 2020; Reddy et al., 2020; Liu et al., 2011), and creating a quick information loss that could explain the premature manifestation of ageing phenotypes in HGPS patients.

At last, it should be noted that, as implicit with the model, the rejuvenation information should be kept silenced in the somatic cells. Indeed, meiotic genes has been shown to be specifically silenced in somatic (or somatic-like) cells (Turner, 2015; Hiriart et al., 2012; Harigaya et al., 2006). In germline (or germline-like) cells, the "old" epigenetic information should be substituted by the "young" epigenetic information, so that, as shown in ectopically induced scenarios (Sarkar et al., 
2020; Lu et al., 2020), decrease (or erase) the aged phenotype. This has already been shown to be the case in physiological conditions (Unal et al., 2011).

\section{Easy-to-check experimental frameworks for the proposed model}

The model proposed in this paper offers a possible explanation for the differences observed in lifespan duration in several examples based on the trade-off between lifespan and complexity (or extrinsic mortality likelihood): 1) most longest-lived organism known are organism showing a lowrisk lifestyle (i.e., comb jellies, sponges, placozoans, hydras, jellyfish, corals, sea anemones, myxozoans, planarias, acoels, red sea urchin, etc.). In those animals the low extrinsic lethality linked to their lifestyles could allow that they have a high non-meiotic reading of "young information" (or rejuvenation) leading them to extends its lifespan by delaying the epigeneticmistakes-based lethality linked to ageing; 2) In organisms with highly efficient protective elements like turtles or clamps, or animals with low risk of predation due their constitutions (i.e., elephants, whales, sharks, etc.). In those cases, a slower speed of the ageing program or a higher non-meiotic rejuvenation could as well give rise to longer lifespans due to low extrinsic mortality likelihood; and 3) A lifestyle difference could as well explain big lifespan differences between phylogenetically related animals (i.e., long lived rodents like naked mole rat (NMR) compared with shorter-lived rats). Experiments could be designed to test (i.e., via epigenetic clocks) how epigenetic drifts are affected in all those animals in comparison with short-lived examples. Note that, since the first version of this manuscript was submitted as a preprint (Marsellach, 2020), another study is indeed showing that NMR show an epigenetic ageing more similar to primates that to more evolutionary related mice, and that inside NMR, which shows a eusocial behaviour (Jarvis, 1981), the NMR queen ages more slowly than NMR non-breeders (Horvath et al., 2021). This results clearly support a mayor role of epigenetics in regulating lifespan, and indirectly backs the epigenetically caused lethality proposed in this paper.

At last, this author detected clues of epigenetically caused lethality in $S$. pombe (Marsellach, 2017). The framework that I developed allowed to put on test many predictions derived from the proposed model, in especial could allow to test whether life and ageing are indeed information-based phenomena by for example uncoupling meiosis from next generation production (Marsellach, 2017). Those experiments, with a careful monitoring of information lost/gain could allow to put on test the above proposed model to describe life and ageing. This author's proposals could help to easily elucidate that lethality due to ageing depends primarily on epigenetics (Marsellach, 2017). This is by far the most provocative and game changer prediction of the model presented in this paper. This author asks the scientific community for help towards achieving the goal of proving this prediction. The serendipity scenario in which these observations were made did not help this author 
from promoting in the academic world in a way that he could do that for himself (Marsellach, 2017).

\section{Conclusion}

This author came up with this theoretical framework from unforeseen and incomplete observations (Marsellach, 2017). The model shows up from these partial observations by asking if they are the exception or the rule. Answering that those partial observations are the rule rather than the exception allows to build the proposed theoretical framework (Marsellach, 2018). Anyway, the model is coherent enough independently of the partial observations obtained by this author and can be built by itself just by the paradigmatic shift of considering ageing as an information-based phenomenon rather than a damage-based one. In other words, by considering damage as the consequence of ageing rather than the cause of it. On top of that, the model is not only fully testable (as detailed above) but has already experimental support by data obtained by Sarkar and colleagues and by $\mathrm{Lu}$ and colleagues which shows that by reprograming aged tissues they could obtain a measurable reduction of the already accumulated damage (Sarkar et al., 2020; Lu et al., 2020). These studies strongly support than damage is a consequence of ageing rather than its cause and provide evidence for an information-based nature of ageing.

In summary, the model proposed in this paper provides both a definition of life and ageing that are complementary and coherent with each other, and, more importantly, are testable. To the best of my knowledge this is a first proposal for an experimental test aimed at answering what life is. Based on all the considerations included in this paper, I would like to encourage the scientific community to consider the information-based nature of ageing as a plausible and more parsimonious explanation for the ageing phenomenon in their future studies, and to consider life and biological sciences as mainly information-based sciences. Biology is all about information handling.

\section{References}

Abel, D. L. (2011). Is life unique. Life (Basel), 2(1), 106-134. https://doi.org/10.3390/life2010106 Ackermann, M., Chao, L., Bergstrom, C. T., \& Doebeli, M. (2007). On the evolutionary origin of aging. Aging Cell, 6(2), 235-244. https://doi.org/10.1111/j.1474-9726.2007.00281.x

Adami, C. (2002). What is complexity. Bioessays, 24(12), 1085-1094. https://doi.org/10.1002/bies.10192

Adami, C. (2012). The use of information theory in evolutionary biology. Ann N Y Acad Sci, 1256, 49-65. https://doi.org/10.1111/j.1749-6632.2011.06422.x 
Allis, C. D., \& Jenuwein, T. (2016). The molecular hallmarks of epigenetic control. Nature Publishing Group, 17(8), 487-500. https://doi.org/10.1038/nrg.2016.59

Ashapkin, V. V., Kutueva, L. I., \& Vanyushin, B. F. (2017). Aging as an Epigenetic Phenomenon. Current Genomics, 18(5), 385-407. https://doi.org/10.2174/1389202918666170412112130

Avery, O. T., Macleod, C. M., \& McCarty, M. (1944). STUDIES ON THE CHEMICAL NATURE OF THE SUBSTANCE INDUCING TRANSFORMATION OF PNEUMOCOCCAL TYPES : INDUCTION OF TRANSFORMATION BY A DESOXYRIBONUCLEIC ACID FRACTION ISOLATED FROM PNEUMOCOCCUS TYPE III. 79(2), 137-158. /pmc/articles/PMC2135445/?report=abstract

Bateson, W., Mendel, G., \& Wheeler, W. M. (1902). Mendel's principles of heredity; a defence by $W$. Bateson. With a translation of Mendel's original papers on hybridisation. University press. https://www.biodiversitylibrary.org/item/100035

Becker, C., \& Weigel, D. (2012). Epigenetic variation: origin and transgenerational inheritance. Curr Opin Plant Biol, 15(5), 562-567. https://doi.org/10.1016/j.pbi.2012.08.004

Bell, C. G., Lowe, R., Adams, P. D., Baccarelli, A. A., Beck, S., Bell, J. T., Christensen, B. C., Gladyshev, V. N., Heijmans, B. T., Horvath, S., Ideker, T., Issa, J. J., Kelsey, K. T., Marioni, R. E., Reik, W., Relton, C. L., Schalkwyk, L. C., Teschendorff, A. E., Wagner, W., . . Rakyan, V. K. (2019). DNA methylation aging clocks: challenges and recommendations. Genome Biol, 20(1), 249. https://doi.org/10.1186/s13059-019-1824-y

Benner, S. A. (2010). Defining life. Astrobiology, 10, 1021-1030. https://doi.org/10.1089/ast.2010.0524

Bertucci, E. M., \& Parrott, B. B. (2020). Is CpG Density the Link between Epigenetic Aging and Lifespan. Trends in Genetics, 36(10), 725-727. https://doi.org/10.1016/j.tig.2020.06.003

Blake, G. E., \& Watson, E. D. (2016). Unravelling the complex mechanisms of transgenerational epigenetic inheritance. Curr Opin Chem Biol, 33, 101-107. https://doi.org/10.1016/j.cbpa.2016.06.008

Bocklandt, S., Lin, W., Sehl, M. E., Sánchez, F. J., Sinsheimer, J. S., Horvath, S., \& Vilain, E. (2011). Epigenetic predictor of age. PLoS ONE, 6(6), e14821. https://doi.org/10.1371/journal.pone.0014821

Bourrat, P., Lu, Q., \& Jablonka, E. (2017). Why the missing heritability might not be in the DNA. BioEssays : news and reviews in molecular, cellular and developmental biology, 39(7), 1700067-1700062. https://doi.org/10.1002/bies.201700067

Boveri, T. (1904). Ergebnisse über die Konstitution der chromatischen Substanz des Zellkerns. G. Fischer. https://www.biodiversitylibrary.org/item/70637

Bruno, C., Carmignac, V., Netchine, I., Choux, C., Duffourd, Y., Faivre, L., Thauvin-Robinet, C., Le Bouc, Y., Sagot, P., \& Bourc'his, D. (2015). Germline correction of an epimutation related to Silver-Russell syndrome. Human Molecular Genetics, 24(12), 3314-3321. https://academic.oup.com/hmg/article/24/12/3314/621800

Cenni, V., Capanni, C., Mattioli, E., Schena, E., Squarzoni, S., Bacalini, M. G., Garagnani, P., Salvioli, S., Franceschi, C., \& Lattanzi, G. (2020). Lamin A involvement in ageing processes. Ageing Research Reviews, 62, 101073. https://doi.org/10.1016/j.arr.2020.101073

Chen, H. L., Li, T., Qiu, X. W., Wu, J., Ling, J. Q., Sun, Z. H., Wang, W., Chen, W., Hou, A., Vu, T. H., Hoffman, A. R., \& Hu, J. F. (2006). Correction of aberrant imprinting of IGF2 in human tumors by nuclear transfer-induced epigenetic reprogramming. EMBO J, 25(22), 53295338. https://doi.org/10.1038/sj.emboj.7601399

Chiavellini, P., Canatelli-Mallat, M., Lehmann, M., Gallardo, M. D., Herenu, C. B., Cordeiro, J. L., Clement, J., \& Goya, R. G. (2021). Aging and rejuvenation - a modular epigenome model. Aging (Albany NY), 13(4), 4734-4746. https://doi.org/10.18632/aging.202712

Coelho, M., Dereli, A., Haese, A., Kühn, S., Malinovska, L., DeSantis, M. E., Shorter, J., Alberti, S., Gross, T., \& Tolić-Nørrelykke, I. M. (2013). Fission Yeast Does Not Age under Favorable Conditions, but Does So after Stress. Current biology : CB, 23(19), 1852.

https://doi.org/10.1016/j.cub.2013.07.084 
Cowley, M., \& Oakey, R. (2012). Resetting for the Next Generation. Molecular Cell, 48(6), 819821. https://doi.org/10.1016/j.molcel.2012.12.007

Crick, F. (1970). Central dogma of molecular biology. Nature, 227(5258), 561.

Currais, A. (2017). The origin of life at the origin of ageing. Ageing Research Reviews, 35, 297300. https://doi.org/10.1016/j.arr.2016.10.007

Danchin, É., Pocheville, A., \& Huneman, P. (2019). Early in life effects and heredity: reconciling neo-Darwinism with neo-Lamarckism under the banner of the inclusive evolutionary synthesis. Philosophical Transactions of the Royal Society B, 374(1770), 20180113. https://royalsocietypublishing.org/doi/pdf/10.1098/rstb.2018.0113

Darwin, C. (1871). On the origin of species. D. Appleton and Co. http://www.biodiversitylibrary.org/item/71804

de Oliveira Martins, L., \& Posada, D. (2016). Infinitely long branches and an informal test of common ancestry. Biology Direct, 11(1). https://doi.org/10.1186/s13062-016-0120-y

de Waal, E., Yamazaki, Y., Ingale, P., Bartolomei, M., Yanagimachi, R., \& McCarrey, J. R. (2012). Primary epimutations introduced during intracytoplasmic sperm injection (ICSI) are corrected by germline-specific epigenetic reprogramming. Proc Natl Acad Sci U S A, 109(11), 4163 4168. https://doi.org/10.1073/pnas.1201990109

de Waal, F. B. M. (2019). Fish, mirrors, and a gradualist perspective on self-awareness. PLoS Biol, 17(2), e3000112. https://doi.org/10.1371/journal.pbio.3000112

Deichmann, U. (2016). Why epigenetics is not a vindication of Lamarckism - and why that matters. Stud Hist Philos Biol Biomed Sci, 57, 80-82. https://doi.org/10.1016/j.shpsc.2016.04.004

Deichmann, U. (2004). Early responses to Avery et al.'s paper on DNA as hereditary material. Historical Studies in the Physical and Biological Sciences, 34(2), 207-232. https://doi.org/ISSN 0890-9997

Denoth-Lippuner, A., \& Jessberger, S. (2019). Mechanisms of cellular rejuvenation. FEBS Lett, 593(23), 3381-3392. https://doi.org/10.1002/1873-3468.13483

Dobzhansky, T. (1935). Maternal Effect as a Cause of the Difference between the Reciprocal Crosses in Drosophila Pseudoöbscura. Proceedings of the National Academy of Sciences, 21(7), 443-446. https://www.ncbi.nlm.nih.gov/pmc/articles/PMC1076622/

Duempelmann, L., Skribbe, M., \& Bühler, M. (2020). Small RNAs in the Transgenerational Inheritance of Epigenetic Information. Trends Genet, 36(3), 203-214. https://doi.org/10.1016/j.tig.2019.12.001

Eriksson, M., Brown, W. T., Gordon, L. B., Glynn, M. W., Singer, J., Scott, L., Erdos, M. R., Robbins, C. M., Moses, T. Y., Berglund, P., Dutra, A., Pak, E., Durkin, S., Csoka, A. B., Boehnke, M., Glover, T. W., \& Collins, F. S. (2003). Recurrent de novo point mutations in lamin A cause Hutchinson-Gilford progeria syndrome. Nature, 423(6937), 293-298. https://doi.org/10.1038/nature01629

Faulk, C., \& Dolinoy, D. C. (2011). Timing is everything: the when and how of environmentally induced changes in the epigenome of animals. Epigenetics, 6(7), 791-797. https://doi.org/10.4161/epi.6.7.16209

Field, A. E., Robertson, N. A., Wang, T., Havas, A., Ideker, T., \& Adams, P. D. (2018). DNA Methylation Clocks in Aging: Categories, Causes, and Consequences. Molecular cell, 71(6), 882-895. https://doi.org/10.1016/j.molcel.2018.08.008

Fuellen, G., Jansen, L., Cohen, A. A., Luyten, W., Gogol, M., Simm, A., Saul, N., Cirulli, F., Berry, A., Antal, P., Köhling, R., Wouters, B., \& Möller, S. (2019). Health and Aging: Unifying Concepts, Scores, Biomarkers and Pathways. Aging Dis, 10(4), 883-900. https://doi.org/10.14336/AD.2018.1030

Fulop, T., Larbi, A., Khalil, A., Cohen, A. A., \& Witkowski, J. M. (2019). Are We Ill Because We Age. Front Physiol, 10, 1508. https://doi.org/10.3389/fphys.2019.01508

Gibbs, W. W. (2014). Biomarkers and ageing: The clock-watcher. [7495]. Nature, 508(7495), 168170. https://doi.org/10.1038/508168a 
Gladyshev, V. N. (2016). Aging: progressive decline in fitness due to the rising deleteriome adjusted by genetic, environmental, and stochastic processes. 15(4), 594-602.

https://doi.org/10.1111/acel.12480

Gladyshev, V. N. (2013). The origin of aging: imperfectness-driven non-random damage defines the aging process and control of lifespan. Trends Genet, 29(9), 506-512. https://doi.org/10.1016/j.tig.2013.05.004

Gladyshev, V. N. (2020). The Ground Zero of Organismal Life and Aging. Trends Mol Med. https://doi.org/10.1016/j.molmed.2020.08.012

Goldberg, A. D., Allis, C. D., \& Bernstein, E. (2007). Epigenetics: A Landscape Takes Shape. Cell, 128(4), 635-638. https://doi.org/10.1016/j.cell.2007.02.006

Greer, E. L., Maures, T. J., Ucar, D., Hauswirth, A. G., Mancini, E., Lim, J. P., Benayoun, B. A., Shi, Y., \& Brunet, A. (2011). Transgenerational epigenetic inheritance of longevity in Caenorhabditis elegans. Nature, 479(7373), 365-371. https://doi.org/10.1038/nature10572

Grewal, S. I. S., \& Klar, A. J. S. (1996). Chromosomal inheritance of epigenetic states in fission yeast during mitosis and meiosis. Cell, 86(1), 95-101.

GURDON, J. B. (1962). Adult frogs derived from the nuclei of single somatic cells. Developmental biology, 4, 256-273.

http://eutils.ncbi.nlm.nih.gov/entrez/eutils/elink.fcgi?dbfrom=pubmed\&amp;id=13903027\&a mp;retmode=ref\&amp;cmd=prlinks

GURDON, J. B., Elsdale, T. R., \& Fischberg, M. (1958). Sexually mature individuals of Xenopus laevis from the transplantation of single somatic nuclei. Nature, 182(4627), 64-65. https://doi.org/10.1038/182064a 0

Hackett, J. A., \& Surani, M. A. (2013). DNA methylation dynamics during the mammalian life cycle. Philos Trans $R$ Soc Lond B Biol Sci, 368(1609), 20110328. https://doi.org/10.1098/rstb.2011.0328

Harigaya, Y., Tanaka, H., Yamanaka, S., Tanaka, K., Watanabe, Y., Tsutsumi, C., Chikashige, Y., Hiraoka, Y., Yamashita, A., \& Yamamoto, M. (2006). Selective elimination of messenger RNA prevents an incidence of untimely meiosis. Nature, 442(7098), 45-50. https://doi.org/10.1038/nature04881

Heard, E., \& Martienssen, R. A. (2014). Transgenerational epigenetic inheritance: myths and mechanisms. Cell, 157(1), 95-109. https://doi.org/10.1016/j.cell.2014.02.045

Hershey, A. D., \& CHASE, M. (1952). Independent functions of viral protein and nucleic acid in growth of bacteriophage. The Journal of General Physiology, 36(1), 39-56. https://doi.org/10.1085/jgp.36.1.39

Hill, P. W. S., Leitch, H. G., Requena, C. E., Sun, Z., Amouroux, R., Roman-Trufero, M., Borkowska, M., Terragni, J., Vaisvila, R., Linnett, S., Bagci, H., Dharmalingham, G., Haberle, V., Lenhard, B., Zheng, Y., Pradhan, S., \& Hajkova, P. (2018). Epigenetic reprogramming enables the transition from primordial germ cell to gonocyte. Nature, 555(7696), 392-396. https://doi.org/10.1038/nature25964

Hirasawa, R., Chiba, H., Kaneda, M., Tajima, S., Li, E., Jaenisch, R., \& Sasaki, H. (2008). Maternal and zygotic Dnmt1 are necessary and sufficient for the maintenance of DNA methylation imprints during preimplantation development. Genes Dev, 22(12), 1607-1616. https://doi.org/10.1101/gad.1667008

Hiriart, E., Vavasseur, A., Touat-Todeschini, L., Yamashita, A., Gilquin, B., Lambert, E., Perot, J., Shichino, Y., Nazaret, N., Boyault, C., Lachuer, J., Perazza, D., Yamamoto, M., \& Verdel, A. (2012). Mmi1 RNA surveillance machinery directs RNAi complex RITS to specific meiotic genes in fission yeast. EMBO J, 31(10), 2296-2308. https://doi.org/10.1038/emboj.2012.105

Horvath, S. (2013). DNA methylation age of human tissues and cell types. Genome biology, 14(10), R115-20. https://doi.org/10.1186/gb-2013-14-10-r115

Horvath, S., Haghani, A., Macoretta, N., Ablaeva, J., Zoller, J. A., Li, C. Z., Zhang, J., Takasugi, M., Zhao, Y., Rydkina, E., Zhang, Z., Emmrich, S., Raj, K., Seluanov, A., Faulkes, C. G., \& 
Gorbunova, V. (2021). DNA methylation clocks show slower progression of aging in naked mole-rat queens. bioRxiv. https://doi.org/10.1101/2021.03.15.435536

Horvath, S., \& Raj, K. (2018). DNA methylation-based biomarkers and the epigenetic clock theory of ageing. Nature Publishing Group, 19(6), 371-384. https://doi.org/10.1038/s41576-018$\underline{0004-3}$

Jablonka, E., \& Lamb, M. (2020). Inheritance systems and the extended synthesis (61(12)). Cambridge University Press. https://www.cambridge.org/core/elements/inheritance-systemsand-the-extended-synthesis/3D1FE025E2368F807142ABAD86062B9D

Jablonka, E., \& Lamb, M. J. (1995). Epigenetic inheritance and evolution: the Lamarckian dimension. Oxford University Press.

https://books.google.com/books?hl=ca\&lr=\&id=B7eH7L 7y3IC\&oi=fnd\&pg=PR14\&dq=Epi genetic + inheritance + and + evolution: + the + Lamarckian+dimension\&ots $=I x R U d m i h R \& \& s i g=3 r$ n5Le7xZMjp9FHs-skXe8fZ6b4

Jarvis, J. U. (1981). Eusociality in a mammal: cooperative breeding in naked mole-rat colonies. Science, 212(4494), 571-573. https://doi.org/10.1126/science.7209555

Jenuwein, T., \& Allis, C. D. (2001). Translating the histone code. Science, 293(5532), 1074-1080. https://doi.org/10.1126/science.1063127

Jiang, S., \& Guo, Y. (2020). Epigenetic Clock: DNA Methylation in Aging. Stem Cells Int, 2020, 1047896. https://doi.org/10.1155/2020/1047896

Jost, J. (2020). Biological information. Theory Biosci, 139(4), 361-370. https://doi.org/10.1007/s12064-020-00327-1

Jost, J. (2021). Biology, geometry and information. Theory Biosci. https://doi.org/10.1007/s12064$\underline{021-00351-9}$

Kempes, C. P., \& Krakauer, D. C. (2021). The Multiple Paths to Multiple Life. J Mol Evol. https://doi.org/10.1007/s00239-021-10016-2

Kirkwood, T. B. (1977). Evolution of ageing. Nature, 270(5635), 301-304. http://eutils.ncbi.nlm.nih.gov/entrez/eutils/elink.fcgi?dbfrom=pubmed\&amp;id=593350\&amp ;retmode $=$ ref\&amp;cmd $=$ prlinks

Kiss, E., Hegedüs, B., Virágh, M., Varga, T., Merényi, Z., Kószó, T., Bálint, B., Prasanna, A. N., Krizsán, K., Kocsubé, S., Riquelme, M., Takeshita, N., \& Nagy, L. G. (2019). Comparative genomics reveals the origin of fungal hyphae and multicellularity. Nat Commun, 10(1), 4080. https://doi.org/10.1038/s41467-019-12085-w

Klosin, A., Casas, E., Hidalgo-Carcedo, C., Vavouri, T., \& Lehner, B. (2017). Transgenerational transmission of environmental information in C. elegans. Science (New York, NY), 356(6335), 320-323. https://doi.org/10.1126/science.aah6412

Kobayashi, H., Sakurai, T., Imai, M., Takahashi, N., Fukuda, A., Yayoi, O., Sato, S., Nakabayashi, K., Hata, K., Sotomaru, Y., Suzuki, Y., \& Kono, T. (2012). Contribution of Intragenic DNA Methylation in Mouse Gametic DNA Methylomes to Establish Oocyte-Specific Heritable Marks. PLoS Genetics, 8(1), e1002440. https://doi.org/10.1371/journal.pgen.1002440

Kono, T., Obata, Y., Wu, Q., Niwa, K., Ono, Y., Yamamoto, Y., Park, E. S., Seo, J.-S., \& Ogawa, H. (2004). Birth of parthenogenetic mice that can develop to adulthood. Nature, 428(6985), 860-864. https://doi.org/10.1038/nature02442

Koonin, E. V. (2014). Calorie restriction à Lamarck. Cell, 158(2), 237-238. https://www.sciencedirect.com/science/article/pii/S0092867414008800

Koonin, E. V. (2015). Why the Central Dogma: on the nature of the great biological exclusion principle. Biology direct, 10(1), 1-5. https://doi.org/10.1186/s13062-015-0084-3

Koonin, E. V., \& Wolf, Y. I. (2009). Is evolution Darwinian or/and Lamarckian. Biology direct, 4(1), 42. https://link.springer.com/article/10.1186/1745-6150-4-42

Koonin, E. V. (2012). Does the central dogma still stand. Biol Direct, 7, 27. https://doi.org/10.1186/1745-6150-7-27

Koonin, E. V., \& Wolf, Y. I. (2010). The common ancestry of life. Biol Direct, 5, 64. https://doi.org/10.1186/1745-6150-5-64 
Koshland, D. E. (2002). Special essay. The seven pillars of life. Science, 295(5563), 2215-2216. https://doi.org/10.1126/science.1068489

Koskela, M., \& Annila, A. (2012). Looking for the Last Universal Common Ancestor (LUCA). Genes, 3(1), 81-87. https://doi.org/10.3390/genes3010081

Krakauer, D., Bertschinger, N., Olbrich, E., Flack, J. C., \& Ay, N. (2020). The information theory of individuality. Theory Biosci, 139(2), 209-223. https://doi.org/10.1007/s12064-020-00313-7

Lange, U. C., \& Schneider, R. (2010). What an epigenome remembers. Bioessays, 32(8), 659-668. https://doi.org/10.1002/bies.201000030

Lapasset, L., Milhavet, O., Prieur, A., Besnard, E., Babled, A., Aït-Hamou, N., Leschik, J., Pellestor, F., Ramirez, J. M., De Vos, J., Lehmann, S., \& Lemaitre, J. M. (2011). Rejuvenating senescent and centenarian human cells by reprogramming through the pluripotent state. Genes Dev, 25(21), 2248-2253. https://doi.org/10.1101/gad.173922.111

Liberman, N., Wang, S. Y., \& Greer, E. L. (2019). Transgenerational epigenetic inheritance: from phenomena to molecular mechanisms. Curr Opin Neurobiol, 59, 189-206. https://doi.org/10.1016/j.conb.2019.09.012

Liu, G.-H., Barkho, B. Z., Ruiz, S., Diep, D., Qu, J., Yang, S.-L., Panopoulos, A. D., Suzuki, K., Kurian, L., Walsh, C., Thompson, J., Boué, S., Fung, H. L., Sancho-Martinez, I., Zhang, K., Yates, J., \& Izpisua Belmonte, J. C. (2011). Recapitulation of premature ageing with iPSCs from Hutchinson-Gilford progeria syndrome. Nature, 472(7342), 221-225. https://doi.org/10.1038/nature09879

Liu, Z., Leung, D., Thrush, K., Zhao, W., Ratliff, S., Tanaka, T., Schmitz, L. L., Smith, J. A., Ferrucci, L., \& Levine, M. E. (2020). Underlying features of epigenetic aging clocks in vivo and in vitro. Aging Cell, 19(10), e13229. https://doi.org/10.1111/acel.13229

Loison, L. (2018). Lamarckism and epigenetic inheritance: a clarification. Biology \& Philosophy, 33(3-4). https://doi.org/10.1007/s10539-018-9642-2

López-León, M., \& Goya, R. G. (2017). The Emerging View of Aging as a Reversible Epigenetic Process. Gerontology, 63(5), 426-431. https://doi.org/10.1159/000477209

López-Maury, L., Marguerat, S. B., \& Bähler, J. (2008). Tuning gene expression to changing environments: from rapid responses to evolutionary adaptation. Nature reviews Genetics, $9(8)$, 583-593. https://doi.org/10.1038/nrg2398

López-Otín, C., Blasco, M. A., Partridge, L., Serrano, M., \& Kroemer, G. (2013). The Hallmarks of Aging. Cell, 153(6), 1194-1217. https://doi.org/10.1016/j.cell.2013.05.039

Lu, Y., Brommer, B., Tian, X., Krishnan, A., Meer, M., Wang, C., Vera, D. L., Zeng, Q., Yu, D., Bonkowski, M. S., Yang, J. H., Zhou, S., Hoffmann, E. M., Karg, M. M., Schultz, M. B., Kane, A. E., Davidsohn, N., Korobkina, E., Chwalek, K., . . Sinclair, D. A. (2020). Reprogramming to recover youthful epigenetic information and restore vision. Nature, 588(7836), 124-129. https://doi.org/10.1038/s41586-020-2975-4

LYON, M. F. (1961). Gene action in the X-chromosome of the mouse (Mus musculus L.). Nature, 190, 372-373. https://doi.org/10.1038/190372a0

Manolio, T. A., Collins, F. S., Cox, N. J., Goldstein, D. B., Hindorff, L. A., Hunter, D. J., McCarthy, M. I., Ramos, E. M., Cardon, L. R., Chakravarti, A., Cho, J. H., Guttmacher, A. E., Kong, A., Kruglyak, L., Mardis, E., Rotimi, C. N., Slatkin, M., Valle, D., Whittemore, A. S., . . Visscher, P. M. (2009). Finding the missing heritability of complex diseases. Nature, 461(7265), 747-753. https://doi.org/10.1038/nature08494

Marioni, R. E., Shah, S., McRae, A. F., Chen, B. H., Colicino, E., Harris, S. E., Gibson, J., Henders, A. K., Redmond, P., Cox, S. R., Pattie, A., Corley, J., Murphy, L., Martin, N. G., Montgomery, G. W., Feinberg, A. P., Fallin, M. D., Multhaup, M. L., Jaffe, A. E., . . Deary, I. J. (2015). DNA methylation age of blood predicts all-cause mortality in later life. Genome biology, 16(1), 25. https://doi.org/10.1186/s13059-015-0584-6

Marsellach, X. (2017). A non-genetic meiotic repair program inferred from spore survival values in fission yeast wild isolates: a clue for an epigenetic ratchet-like model of ageing? bioRxiv. https://doi.org/10.1101/223685 
Marsellach, X. (2018). A non-Lamarckian model for the inheritance of the epigenetically-coded phenotypic characteristics: a new paradigm for Genetics, Genomics and, above all, Ageing studies. bioRxiv. https://doi.org/10.1101/492280

Marsellach, X. (2020). The Principle of Continuous Biological Information Flow as the Fundamental Foundation for the Biological Sciences. Implications for Ageing Research. Preprints. https://doi.org/10.20944/preprints202012.0506.v1

McCarrey, J. R. (2014). Distinctions between transgenerational and non-transgenerational epimutations. Molecular and cellular endocrinology, 398(1-2), 13-23. https://www.sciencedirect.com/science/article/pii/S0303720714002202

McCLINTOCK, B. (1951). Chromosome organization and genic expression. Cold Spring Harbor symposia on quantitative biology, 16, 13-47.

http://eutils.ncbi.nlm.nih.gov/entrez/eutils/elink.fcgi?dbfrom=pubmed\&amp;id=14942727\&a $\underline{\mathrm{mp} ; \text { retmode }=\text { ref\&amp; } \mathrm{cmd}=\text { prlinks }}$

McCrory, C., Fiorito, G., Hernandez, B., Polidoro, S., O’Halloran, A. M., Hever, A., Ni Cheallaigh, C., Lu, A. T., Horvath, S., \& Vineis, P. (2020). GrimAge outperforms other epigenetic clocks in the prediction of age-related clinical phenotypes and all-cause mortality. The Journals of Gerontology: Series A. https://doi.org/10.1093/gerona/glaa286/5992253

McDonald, R. B. (2013). Biology of Aging. Garland Science. http://books.google.es/books?id=6TImAgAAQBAJ\&hl=\&source=gbs_api

McGrath, J., \& Solter, D. (1984). Completion of mouse embryogenesis requires both the maternal and paternal genomes. Cell, 37(1), 179-183.

http://eutils.ncbi.nlm.nih.gov/entrez/eutils/elink.fcgi?dbfrom=pubmed\&amp;id=6722870\&am p;retmode $=$ ref\&amp;cmd $=$ prlinks

Mendel, G. (1866). Versuche über Plflanzenhybriden. Verhandlungen des naturforschenden Vereines in Brünn, Bd. IV für das Jahr 1865, Abhandlungen, 3-47 (295).

Miska, E. A., \& Ferguson-Smith, A. C. (2016). Transgenerational inheritance: Models and mechanisms of non-DNA sequence-based inheritance. Science (New York, NY), 354(6308), 59-63. https://doi.org/10.1126/science.aaf4945

Moger-Reischer, R. Z., \& Lennon, J. T. (2019). Microbial ageing and longevity. Nature Reviews Microbiology, 17(11), 679-690. https://doi.org/10.1038/s41579-019-0253-y

Morange, M. (2009). The Central Dogma of molecular biology. Resonance, 14(3), 236-247.

Morgan, T. H. (1915). The mechanism of Mendelian heredity. Holt. https://www.biodiversitylibrary.org/item/27295

MULLER, H. J., \& Altenburg, E. (1930). The Frequency of Translocations Produced by X-Rays in Drosophila. Genetics, 15(4), 283-311. https://www.ncbi.nlm.nih.gov/pmc/PMC1201066/

Niehrs, C., \& Calkhoven, C. F. (2020). Emerging Role of C/EBP $\beta$ and Epigenetic DNA Methylation in Ageing. Trends Genet, 36(2), 71-80. https://doi.org/10.1016/j.tig.2019.11.005

O'Kane, C. J., \& Hyland, E. M. (2019). Yeast epigenetics: the inheritance of histone modification states. Biosci Rep, 39(5). https://doi.org/10.1042/BSR20182006

Ocampo, A., Reddy, P., Martínez-Redondo, P., Platero-Luengo, A., Hatanaka, F., Hishida, T., Li, M., Lam, D., Kurita, M., Beyret, E., Araoka, T., Vazquez-Ferrer, E., Donoso, D., Roman, J. L., Xu, J., Rodriguez Esteban, C., Nuñez, G., Nuñez Delicado, E., Campistol, J. M., . . Izpisua Belmonte, J. C. (2016). In Vivo Amelioration of Age-Associated Hallmarks by Partial Reprogramming. Cell, 167(7), 1719-1733.e12.

https://doi.org/10.1016/j.cell.2016.11.052

Ogrodnik, M., Salmonowicz, H., \& Gladyshev, V. N. (2019). Integrating cellular senescence with the concept of damage accumulation in aging: Relevance for clearance of senescent cells. Aging Cell, 18(1), e12841. https://doi.org/10.1111/acel.12841

Penny, D., Foulds, L. R., \& Hendy, M. D. (1982). Testing the theory of evolution by comparing phylogenetic trees constructed from five different protein sequences. Nature, 297(5863), 197 200. https://doi.org/10.1038/297197a0 
Perez, M. F., \& Lehner, B. (2018). Intergenerational and transgenerational epigenetic inheritance in animals. Nature cell biology, 43(83), 1-9. https://doi.org/10.1038/s41556-018-0242-9

Prokopuk, L., Western, P. S., \& Stringer, J. M. (2015). Transgenerational epigenetic inheritance: adaptation through the germline epigenome? Epigenomics, 7(5), 829-846. https://doi.org/10.2217/epi.15.36

Prusiner, S. B. (1982). Novel proteinaceous infectious particles cause scrapie. Science, 216(4542), 136-144. https://doi.org/10.1126/science.6801762

Prusiner, S. B., \& McCarty, M. (2006). Discovering DNA Encodes Heredity and Prions are Infectious Proteins. Annual review of genetics, 40(1), 25-45. https://doi.org/10.1146/annurev.genet.40.121505.133522

Ragunathan, K., Jih, G., \& Moazed, D. (2015). Epigenetic inheritance uncoupled from sequencespecific recruitment. Science, 348(6230). https://www.ncbi.nlm.nih.gov/pmc/articles/PMC4385470

Recht, J., Tsubota, T., \& Tanny..., J. C. (2006). Histone chaperone Asf1 is required for histone H3 lysine 56 acetylation, a modification associated with $\mathrm{S}$ phase in mitosis and meiosis.

Proceedings of the .... https://www.pnas.org/content/103/18/6988.short

Reddy, P., Shao, Y., Hernandez-Benitez, R., Nuñez Delicado, E., \& Izpisua Belmonte, J. C. (2020). First progeria monkey model generated using base editor. Protein Cell, 11(12), 862-865. https://doi.org/10.1007/s 13238-020-00765-z

Reik, W. (2007). Stability and flexibility of epigenetic gene regulation in mammalian development. Nature, 447(7143), 425-432. https://doi.org/10.1038/nature05918

Rodríguez-Matellán, A., Alcazar, N., Hernández, F., Serrano, M., \& Ávila, J. (2020). In Vivo Reprogramming Ameliorates Aging Features in Dentate Gyrus Cells and Improves Memory in Mice. Stem Cell Reports. https://doi.org/10.1016/j.stemcr.2020.09.010

Rose, M. R. (1994). Evolutionary Biology of Aging. Oxford University Press. https://play.google.com/store/books/details?id=LZ1mY1G-myoC\&source=gbs_api

Rusche, L. N., Kirchmaier, A. L., \& Rine, J. (2003). The establishment, inheritance, and function of silenced chromatin in Saccharomyces cerevisiae. Annu Rev Biochem, 72, 481-516. https://doi.org/10.1146/annurev.biochem.72.121801.161547

Ryan, C. P. (2020). "Epigenetic clocks": Theory and applications in human biology. Am J Hum Biol, e23488. https://doi.org/10.1002/ajhb.23488

Sarkar, T. J., Quarta, M., Mukherjee, S., Colville, A., Paine, P., Doan, L., Tran, C. M., Chu, C. R., Horvath, S., Qi, L. S., Bhutani, N., Rando, T. A., \& Sebastiano, V. (2020). Transient nonintegrative expression of nuclear reprogramming factors promotes multifaceted amelioration of aging in human cells. Nat Commun, 11(1), 1545. https://doi.org/10.1038/s41467-02015174-3

Senaldi, L., \& Smith-Raska, M. (2020). Evidence for germline non-genetic inheritance of human phenotypes and diseases. Clin Epigenetics, 12(1), 136. https://doi.org/10.1186/s13148-02000929-y

Shapiro, J. A. (2009). Revisiting the central dogma in the 21 st century. Ann N Y Acad Sci, 1178, 628. https://doi.org/10.1111/j.1749-6632.2009.04990.x

Sinclair, D. A., \& LaPlante, M. D. (2019). Lifespan. http://books.google.es/books?id=ZhfMzQEACAAJ\&hl=\&source=gbs api

Skvortsova, K., Iovino, N., \& Bogdanović, O. (2018). Functions and mechanisms of epigenetic inheritance in animals. Nat Rev Mol Cell Biol, 19(12), 774-790. https://doi.org/10.1038/s41580-018-0074-2

Smith, Z. D., Chan, M. M., Mikkelsen, T. S., Gu, H., Gnirke, A., Regev, A., \& Meissner, A. (2012). A unique regulatory phase of DNA methylation in the early mammalian embryo. Nature, 484(7394), 339-344. https://doi.org/10.1038/nature10960

Speijer, D., Lukes, J., \& Elias, M. (2015). Sex is a ubiquitous, ancient, and inherent attribute of eukaryotic life. Proceedings of the National Academy of Sciences, 112(29), 8827-8834. https://doi.org/10.1073/pnas.1501725112 
Sutton, W. S. (1903). The Chromosomes in Heredity. Biological Bulletin, 4(5), 231-251. https://doi.org/10.2307/1535741

Takahashi, K., \& Yamanaka, S. (2006). Induction of Pluripotent Stem Cells from Mouse Embryonic and Adult Fibroblast Cultures by Defined Factors. Cell, 126(4), 663-676. https://doi.org/10.1016/j.cell.2006.07.024

Tan, C. L., \& Anderson, E. (2020). The New Central Dogma of Molecular Biology. https://www.researchgate.net/publication/340062231_The_New_Central_Dogma_of_Molecul ar_Biology

Tetz, V. V., \& Tetz, G. V. (2020). A new biological definition of life. Biomol Concepts, 11(1), 1-6. https://doi.org/10.1515/bmc-2020-0001

Theobald, D. L. (2010). A formal test of the theory of universal common ancestry. Nature, 465(7295), 219-222. https://doi.org/10.1038/nature09014

Tirard, S., Morange, M., \& Lazcano, A. (2010). The definition of life: a brief history of an elusive scientific endeavor. Astrobiology, 10, 1003-1009. https://doi.org/10.1089/ast.2010.0535

Turner, J. M. (2015). Meiotic Silencing in Mammals. Annu Rev Genet, 49, 395-412. https://doi.org/10.1146/annurev-genet-112414-055145

Unal, E., Kinde, B., \& Amon, A. (2011). Gametogenesis Eliminates Age-Induced Cellular Damage and Resets Life Span in Yeast. Science (New York, NY), 332(6037), 1554-1557. https://doi.org/10.1126/science.1204349

Velasco, J. (2018). Universal common ancestry, LUCA, and the Tree of Life: three distinct hypotheses about the evolution of life. Biology \& Philosophy, 33(5-6). https://doi.org/10.1007/s10539-018-9641-3

Virchow, R. (1859). Die Cellularpathologie in ihrer Begründung auf physiologische und pathologische Gewebelehre. Hirschwald. https://books.google.es/books?id=DBE3AQAAMAAJ

Vitas, M., \& Dobovišek, A. (2019). Towards a General Definition of Life. Orig Life Evol Biosph, 49(1-2), 77-88. https://doi.org/10.1007/s11084-019-09578-5

WADDINGTON, C. H. (1942). CANALIZATION OF DEVELOPMENT AND THE INHERITANCE OF ACQUIRED CHARACTERS. Nature, 150(3811), 563-565. https://doi.org/10.1038/150563a0

Wang, F., Zhang, W., Yang, Q., Kang, Y., Fan, Y., Wei, J., Liu, Z., Dai, S., Li, H., Li, Z., Xu, L., Chu, C., Qu, J., Si, C., Ji, W., Liu, G. H., Long, C., \& Niu, Y. (2020). Generation of a Hutchinson-Gilford progeria syndrome monkey model by base editing. Protein Cell, 11, 809824. https://doi.org/10.1007/s13238-020-00740-8

WATSON, J. D., \& CRICK, F. H. (1953a). Molecular structure of nucleic acids; a structure for deoxyribose nucleic acid. Nature, 171(4356), 737-738. https://doi.org/10.1038/171737a0

WATSON, J. D., \& CRICK, F. H. (1953b). Genetical implications of the structure of deoxyribonucleic acid. Nature, 171(4361), 964-967. https://doi.org/10.1038/171964b0

Xavier, M. J., Roman, S. D., Aitken, R. J., \& Nixon, B. (2019). Transgenerational inheritance: how impacts to the epigenetic and genetic information of parents affect offspring health. Hum Reprod Update, 25(5), 518-540. https://doi.org/10.1093/humupd/dmz017

Yang, J.-H., Hayano, M., Griffin, P., Amorim, J., Bonkowski, M., Apostolides, J., Blanchette, M., Munding, E., Bhakta, M., Salfati, E., Lu, Y., Vera, D., Ross, J., Coppotelli, G., Chew, Y., Guo, W., Yang, X., Meer, M., Tian, X., . . Sinclair, D. (2021). Loss of Epigenetic Information as a Cause of Mammalian Aging. SSRN Electronic Journal. https://doi.org/10.2139/ssrn.3951490

Yu, R., Wang, X., \& Moazed, D. (2018). Epigenetic inheritance mediated by coupling of RNAi and histone H3K9 methylation. Nature, 558(7711), 615-619. https://doi.org/10.1038/s41586-018$\underline{0239-3}$

Zhang, B., \& Gladyshev, V. N. (2020). How can aging be reversed? Exploring rejuvenation from a damage-based perspective. Genetics \& Genomics Next, e10025.

https://doi.org/10.1002/ggn2.10025 
Zhang, W., Qu, J., Liu, G. H., \& Belmonte, J. C. I. (2020). The ageing epigenome and its rejuvenation. Nat Rev Mol Cell Biol, 21(3), 137-150. https://doi.org/10.1038/s41580-019$\underline{0204-5}$ 